\title{
Robust Visual Responses and Normal Retinotopy in Primate Lateral Geniculate Nucleus following Long-term Lesions of Striate Cortex
}

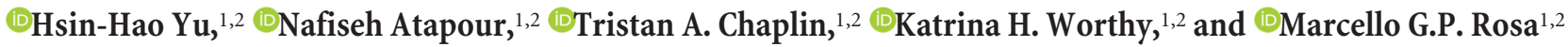 \\ ${ }^{1}$ Department of Physiology and Biomedicine Research Institute, Monash University, Clayton, 3800 Victoria, Australia and ${ }^{2}$ Australian Research Council \\ Centre of Excellence for Integrative Brain Function, Monash University Node, Clayton, 3800 Victoria, Australia
}

Lesions of striate cortex (V1) trigger massive retrograde degeneration of neurons in the LGN. In primates, these lesions also lead to scotomas, within which conscious vision is abolished. Mediation of residual visual capacity within these regions (blindsight) has been traditionally attributed to an indirect visual pathway to the extrastriate cortex, which involves the superior colliculus and pulvinar complex. However, recent studies have suggested that preservation of the LGN is critical for behavioral evidence of blindsight, raising the question of what type of visual information is channeled by remaining neurons in this structure. A possible contribution of LGN neurons to blindsight is predicated on two conditions: that the neurons that survive degeneration remain visually responsive, and that their receptive fields continue to represent the region of the visual field inside the scotoma. We tested these conditions in male and female marmoset monkeys (Callithrix jacchus) with partial V1 lesions at three developmental stages (early postnatal life, young adulthood, old age), followed by long recovery periods. In all cases, recordings from the degenerated LGN revealed neurons with well-formed receptive fields throughout the scotoma. The responses were consistent and robust, and followed the expected eye dominance and retinotopy observed in the normal LGN. The responses had short latencies and preceded those of neurons recorded in the extrastriate middle temporal area. These findings suggest that the pathway that links LGN neurons to the extrastriate cortex is physiologically viable and can support residual vision in animals with $\mathrm{V} 1$ lesions incurred at various ages.

Key words: blindsight; lesion; LGN; marmoset; plasticity; primate

Significance Statement

Patients with a lesion of the primary visual cortex (V1) can retain certain visually mediated behaviors, particularly if the lesion occurs early in life. This phenomenon ("blindsight") not only sheds light on the nature of consciousness, but also has implications for studies of brain circuitry, development, and plasticity. However, the pathways that mediate blindsight have been the subject of debate. Recent studies suggest that projections from the LGN might be critical, but this finding is puzzling given that the lesions causes severe cell death in the LGN. Here we demonstrate in monkeys that the surviving LGN neurons retain a remarkable level of visual function and could therefore be the source of the visual information that supports blindsight.

\section{Introduction}

In primates, visual function is dominated by the pathway which transmits visual information from the retina, via the lateral geniculate nucleus (LGN), to the primary visual cortex (V1). Although lesions of V1 lead to blindness (Holmes, 1918; Horton and Hoyt, 1991), it is well documented that residual visual function can be

\section{Received Jan. 22, 2018; revised March 4, 2018; accepted March 10, 2018}

Author contributions: H.-H.Y. and M.G.P.R. edited the paper; H.-H.Y. and M.G.P.R. designed research; H.-H.Y., N.A., T.A.C., K.H.W., and M.G.P.R. performed research; H.-H.Y., N.A., and M.G.P.R. analyzed data; H.-H.Y. wrote the paper.

This work was supported by National Health and Medical Research Council Grants 1122220 and 1128755, Australian Research Council Grant DE140101505, and Australian Research Council Centre of Excellence for Integrative Brain Function CE140100007. We thank Janssen-Cilag for donation of sufentanil citrate. retained within scotomas caused by V1 lesions, including (largely subconscious) abilities to locate some types of stimulus, and even to coarsely evaluate their characteristics ("blindsight") (Sanders et al., 1974). These observations indicate that other thalamic projections can convey retinal inputs directly to the extrastriate cortex, bypassing V1 (Leopold, 2012).

V1 lesions have long been known to trigger large-scale retrograde degeneration of neurons in the LGN (Matthews et al., 1960;

The authors declare no competing financial interests.

Correspondence should be addressed to Dr. Hsin-Hao Yu, Department of Physiology, Monash University, 26 Innovation Walk, Clayton, 3800 VIC, Australia. E-mail: hsin-hao.yu@monash.edu.

DOI:10.1523/JNEUROSCI.0188-18.2018

Copyright $@ 2018$ the authors $\quad 0270-6474 / 18 / 383955-16 \$ 15.00 / 0$ 
Mihailović et al., 1971; Cowey and Stoerig, 1989; Atapour et al., 2017). Consequently, the dominant hypothesis in the literature has been that blindsight is primarily mediated by a polysynaptic pathway that sequentially involves the retina, superior colliculus, pulvinar complex, and extrastriate cortex (for review, see Cowey, 2010). Indeed, physiological studies have reported that the integrity of the superior colliculus is important for the preservation of visually evoked responses in the extrastriate middle temporal area (MT) following V1 lesions (Rodman et al., 1990), and have confirmed the existence of the hypothesized collicular relay in the pulvinar complex of normal animals (Berman and Wurtz, 2010, 2011). Other studies have demonstrated that retinal cells make direct synapses with a small population of pulvinar neurons, which, in turn, project directly to MT (e.g., Warner et al., 2010), thereby revealing another potential anatomical pathway by which neurons in the pulvinar complex could mediate aspects of blindsight.

However, a key question that has remained unanswered is the physiological state of the LGN following V1 lesions. This issue has gained importance in view of mounting evidence that the preservation of functional blindsight requires the integrity of the LGN and its pathways to extrastriate cortex, as revealed by both thalamic inactivation studies in macaque monkeys (Schmid et al., 2010) and tractography analyses in humans (Ajina et al., 2015). Although it has been well documented that a small, but distinct, population of LGN neurons projects directly to extrastriate cortex (Benevento and Yoshida, 1981; Fries, 1981; Yukie and Iwai, 1981; Sincich et al., 2004; Warner et al., 2010), it remains unknown whether the neurons that survive degeneration following V1 lesions continue to respond to visual stimulation, and, if so, what physiological properties they retain. Of particular importance is determining whether the receptive fields of surviving neurons continue to represent the visual field within the scotomas created by V1 lesions. Given that lesion-induced reorganization of adult retinotopic maps has been documented in various structures of the visual system following the removal of afferent input (for review, see Wandell and Smirnakis, 2009), it is possible that the surviving neurons in fact convey visual information that originates in intact parts of the visual field, including the edges of the scotomas, a scenario that would point to a limited contribution to blindsight.

Here we report on the retinotopy and response properties of LGN neurons in marmosets that were allowed to recover for periods of $>17$ months following a V1 lesion. Because the extent of preservation of visual function in both humans and monkeys changes with the age at which the lesions occur (Blythe et al., 1987; Moore et al., 1996; Gross et al., 2004; Werth, 2006; Guzzetta et al., 2010; Silvanto and Rees, 2011; Yu et al., 2013; Warner et al., 2015), we compared the effects of lesions at three different time points: during the first few postnatal weeks, in early adulthood, and in late life. Our results indicate that the LGN neurons that escape degeneration show a remarkable degree of preservation of visual function within the scotoma, compatible with the hypothesis that this structure forms a viable pathway for the mediation of residual visual function following lesions incurred at any age.

\section{Materials and Methods}

Partial unilateral lesions of V1 were placed in six common marmosets (Callithrix jacchus). Table 1 summarizes the sex and the age of the animals when the lesion surgeries were performed. All experiments were conducted in accordance with the Australian Code of Practice for the Care and Use of Animals for Scientific Purposes. All procedures were approved by the Monash University Animal Ethics Experimentation
Table 1. Summary of the timing of unilateral V1 lesions, and sizes of the physiological scotoma

\begin{tabular}{|c|c|c|c|c|c|c|c|}
\hline $\begin{array}{l}\text { Age } \\
\text { group }\end{array}$ & Case ID & Sex & $\begin{array}{l}\text { Age of animal } \\
\text { at lesion }\end{array}$ & $\begin{array}{l}\text { Recovery } \\
\text { time }\end{array}$ & $\begin{array}{l}\text { Scotoma } \\
\text { length }\left({ }^{\circ}\right)\end{array}$ & $\begin{array}{l}\text { Scotoma } \\
\text { width }\left(^{\circ}\right)\end{array}$ & $\begin{array}{l}\% \text { of } \mathrm{V} 1 \\
\text { lesioned }\end{array}$ \\
\hline \multirow[t]{2}{*}{ Infant } & W2E & Female & $1 w 4 d$ & $1 y 8 m 2 d$ & 56.2 & 43.2 & 82 \\
\hline & W6E & Female & $5 w 5 d$ & $2 y 9 \mathrm{~m} 17 \mathrm{~d}$ & 44.4 & 44.4 & 73 \\
\hline \multirow[t]{2}{*}{ Adult } & WA5 & Female & $3 y 2 m 29 d$ & $1 y 7 m 22 d$ & 64.8 & 40.0 & 77 \\
\hline & WA6 & Male & $1 y 11 m 12 d$ & $1 y 5 m 19 d$ & 60.6 & 36.6 & 70 \\
\hline \multirow[t]{2}{*}{ Late-life } & WG3 & Female & $10 y 5 m 19 d$ & $1 y 6 \mathrm{~m} 10 \mathrm{~d}$ & 75.6 & 64.0 & 93 \\
\hline & WG4 & Female & $9 y 1 m 29 d$ & $1 y 5 \mathrm{~m} 19 \mathrm{~d}$ & 62.0 & 35.4 & 82 \\
\hline
\end{tabular}

Table 2. Estimated volumes of the LGN in the three age groups ${ }^{a}$

\begin{tabular}{lllll}
\hline $\begin{array}{l}\text { Age } \\
\text { group }\end{array}$ & Case ID & $\begin{array}{l}\text { Ipsilateral } \\
\text { LGN volume }\left(\mathrm{mm}^{3}\right)\end{array}$ & $\begin{array}{l}\text { Contralateral } \\
\text { LGN volume }\left(\mathrm{mm}^{3}\right)\end{array}$ & $\begin{array}{l}\text { Ipsilateral/ } \\
\text { contralateral ratio (\%) }\end{array}$ \\
\hline \multirow{2}{*}{ Infant } & W2E & 5.1 & 10.13 & 50.3 \\
& W6E & 5.29 & 10.03 & 52.7 \\
Adult & WA5 & 5.99 & 10.54 & 56.8 \\
& WA6 & 6.40 & 11.06 & 57.9 \\
Late-life & WG3 & 5.32 & 11.19 & 47.5 \\
& WG4 & 7.04 & 11.38 & 61.9
\end{tabular}

${ }^{a}$ The averaged ipsilateral/contralateral volume ratios for the infant, adult, and late-life groups were $51.5 \%, 57.4 \%$, and $54.7 \%$, respectively. The average volumes of the contralateral LGN were estimated $10.08,10.8$, and $11.29 \mathrm{~mm}^{3}$ for the three groups, which were comparable with the median LGN volume of 4 adult marmosets with no V1 lesions, $10.31 \mathrm{~mm}^{3}$, as reported by Atapour et al. (2017). These values were also comparable with previous estimates of the volume of the marmoset LGN (Fritschy and Garey, 1986a; White et al., 1998; Warner et al., 2015).

Committee, which also monitored the health and well-being of the animals throughout the experiments. The experimental procedures were similar to those described by Yu et al. (2013).

Cortical lesions. The animals were anesthetized with isoflurane $(2 \%-$ $3 \%)$. Under sterile conditions, a craniotomy was made over the occipital pole of the left hemisphere. Using a fine-tipped cautery, an excision was then made of all the cortical tissue caudal to a plane extending from the dorsal surface of the occipital lobe to the cerebellar tentorium, across the entire mediolateral extent of the cortex. This type of lesion results in destruction of large portions of V1, as well as the white matter subjacent to this area (which includes optic radiation and corticothalamic projection fibers). However, there is minimal or no damage to most extrastriate areas, with possible exception of parts of V2 adjacent to the V1 border (Rosa et al., 2000). In addition, it is possible that compromised function in V1 extended beyond the tissue that was removed. This was why we used physiological criteria to estimate the extent of the visual field representation in V1 affected by the lesions, in each case (see details below).

After application of hemostatic microspheres, the exposed cortex and cerebellum were protected with ophthalmic film, and the cavity was filled with Gelfoam. The skull was reconstructed, the skin was sutured, and antibiotics (Norocillin, $0.05 \mathrm{ml}$, i.m.) were administered. The marmosets were placed in a humidicrib until recovery of movement, after which they were returned to parental care (Cases W2E and W6E) or kept under close observations for a period of 1 week. Subsequently, and throughout the postlesion period, they were housed in large cages with family groups, having access to both indoor and outdoor environments.

Electrophysiological recordings. Each of the animals underwent a single recording session, using the same protocol used in previous studies in our laboratory (e.g., Yu and Rosa, 2010; Yu et al., 2012, 2013). They were premedicated with diazepam $(3.0 \mathrm{mg} / \mathrm{kg})$ and atropine $(0.2 \mathrm{mg} / \mathrm{kg})$, and anesthesia was induced (30 min later) with alfaxalone $(10 \mathrm{mg} / \mathrm{kg})$. After tracheotomy and craniotomy, they were administered an intravenous infusion of a mixture of pancuronium bromide $(0.1 \mathrm{mg} / \mathrm{kg} / \mathrm{h})$, sufentanil $(6-8 \mu \mathrm{g} / \mathrm{kg} / \mathrm{h})$, and dexamethasone $(0.4 \mathrm{mg} / \mathrm{kg} / \mathrm{h})$, in a saline-glucose solution. During the recording sessions, they were also ventilated with nitrous oxide and oxygen (7:3). This protocol has been shown to produce long-lasting anesthesia in other experiments where no neuromuscular block was used (Rajan et al., 2013; Lui et al., 2015). Tungsten microelectrodes $(\sim 1 \mathrm{M} \Omega)$ were inserted into the cortex in the vertical stereotaxic plane. Amplification and filtering were achieved via an AM Systems model 1800 microelectrode alternating current amplifier. 

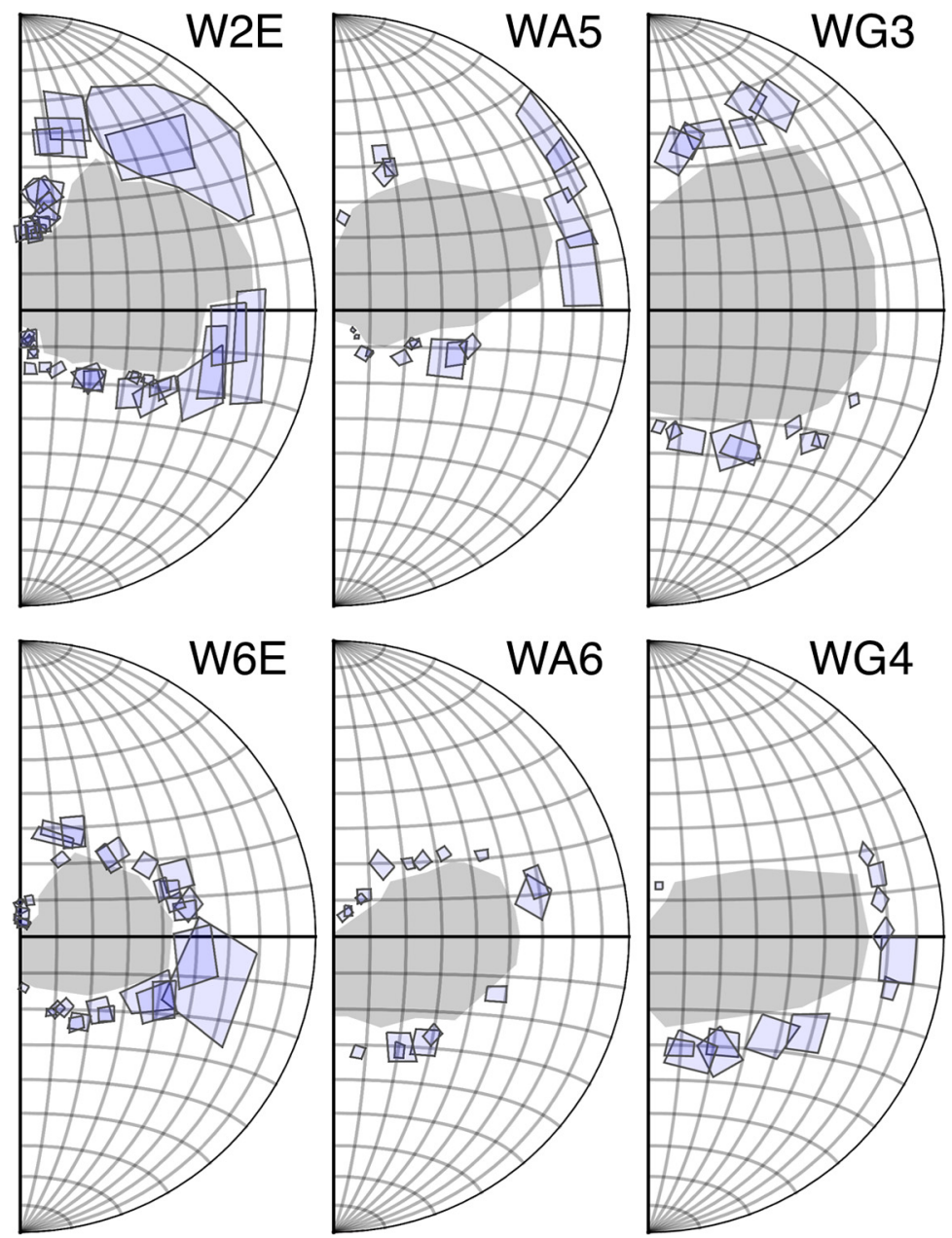

Figure 1. The spatial extents of the physiological scotomas (the areas shaded in gray) were estimated by manually mapping the receptive fields of V1 neurons (indicated by rectangles) close to the edge of the lesions. In Cases WA5 and WG4, the upper visual field boundaries of the physiological scotoma were estimated from the recording sites in the LGN, using the point where the background activity abruptly increased.

Stimulus presentation and data acquisition. Stimuli were presented monocularly in a room with mesopic background illumination. A computer-controlled video projector $(640 \times 480$ resolution, refresh rate $85 \mathrm{~Hz}$ ) was used to generate visual patterns on the surface of a hemispheric screen ( $90 \mathrm{~cm}$ diameter), which was centered on the right (contralateral) eye (Yu and Rosa, 2010; Yu et al., 2013). A modified version of Expo (Release 1.5.0), designed by Dr. Peter Lennie and others, was used for stimulus generation and data acquisition. Hard contact lenses, selected by retinoscopy and positioned over a film of carmellose sodium, were used to focus both eyes on the hemispheric screen.

Neural activity was sampled at intervals of 100-200 $\mu \mathrm{m}$ during each penetration. For each multiunit cluster, we first used a spot of light to determine an outline of the receptive field. The single-unit activity was isolated interactively, using the thresholding and template matching features of the program Expo. To quantitatively map the receptive field envelope, bright squares (contrast: $86 \%$ ) were displayed in multiple locations around the estimated receptive field center, according to a grid $(8 \times 8$ or $12 \times 12$ locations). The stimuli were typically on for $0.2 \mathrm{~s}$, and off for $0.2 \mathrm{~s}$, and were repeated 8 to 20 times at each location. The size of the squares was adjusted for each cell so that the entire receptive field was included, as well as the immediate surround (see Fig. 3 ). The size of the squares varied between $0.5^{\circ}$ and $4^{\circ}$ of visual arc, depending on the receptive field location and eccentricity. For most of the receptive fields shown in Figures 4-6, the mapping stimulus was a bright broadband (white) flashing square $\left(4.0 \mathrm{~cd} / \mathrm{m}^{2}\right)$ presented on a dark gray $\left(0.3 \mathrm{~cd} / \mathrm{m}^{2}\right)$ background. For LGN units with OFF responses, the stimulus was a dark flashing square presented on a bright background. In sites where the white stimulus was unable to elicit responses strong enough to delineate the receptive fields, we also attached a Kodak Wratten 47B deep blue filter in front of the lens of the projector to eliminate wavelengths $>500 \mathrm{~nm}$. This filter was chosen because its transmission spectrum closely resembles the sensitivity function of the blue cone in the retina (peak transmission at $430 \mathrm{~nm}$ ).

For mapping the scotoma boundaries in V1 and MT receptive fields, the stimulus was presented monocularly to the eye contralateral to the recording sites. While recording in $\mathrm{V} 1$, we mapped several V1 receptive fields through stimulation of either eye and calculated the mean binocular disparity between the centers of the receptive fields. This was used in Figures $4-6$, to translate the locations of receptive field mapped with the ipsilateral eye to coordinates centered on the contralateral eye.

Recording procedures. Each electrophysiological experiment consisted of three phases:

(1) The physiological scotoma was estimated by mapping the receptive fields very close to the edge of the V1 lesions (see Fig. 1). A small spot or slit of light was projected onto a hemispheric screen positioned in front of the animal with a manually operated light source. The experimenter directly drew the boundaries of the receptive fields as rectangles on the hemisphere, which were digitized after the recording session.

(2) In all cases except W6E, a small number of electrode penetrations (3-5) were made in area MT to ensure that the extrastriate cortex received visual inputs. Area MT in the hemisphere ipsilateral to the lesion was located with stereotaxic coordinates (Rosa and Elston, 1998; Paxinos et al., 2012) using the same procedure as in Yu et al. (2013). MT receptive fields were manually mapped except for those located inside the scotoma, which were mapped qualitatively with the stimuli described above.

(3) The LGN was located by first targeting its stereotaxic coordinates according to Paxinos et al. (2012), although detailed mapping of the region surrounding the coordinates was also usually undertaken to confirm the location of the LGN. In these penetrations, we first advanced the electrode $5000 \mu \mathrm{m}$ into the brain and then proceeded in $100 \mu \mathrm{m}$ steps until background activity could be detected. For each site, we also established eye dominance by flashing a stimulus monocularly to each eye. The receptive fields were then quantitatively mapped as described above.

In Case W6E, the recording time did not allow systematic mapping of MT. In Case WA5, the upper boundary of the physiological scotoma was sparsely sampled (see Fig. 1), and in Case WG4, it could not be reliably established because small displacement of the recording site resulted in a large change in receptive field position in the far peripheral visual field (due to low cortical magnification). We estimated the upper boundaries of the scotomas in these 2 cases with recording sites in the LGN, where the background activity abruptly increased, indicating that the electrode went outside the lesion projection zone (see below). These estimates were validated based on histological reconstruction of the $\mathrm{V} 1$ lesion and the cortical magnification factor reported by Chaplin et al. (2013).

Quantification of receptive fields. The envelopes of the receptive fields were fitted with the 5-parameter Fisher-Bingham function (i.e., Gaussian distribution defined on the sphere) (Yu and Rosa, 2010; Yu et al., 2013). The elliptic boundary of a receptive field was estimated as the contour at $85 \%$ of the peak value of the fitted function (see Fig. 3). To express the diameter of the elliptic boundary with a single number (seeFig. 9), we 
calculated the diameter of a circular receptive field with the same surface area as the fitted ellipse. This was accomplished by first calculating the surface area $A$ of the elliptic receptive field (unit: square degree). The diameter of the circular receptive field (unit: degree) is as follows: $2 \times \cos ^{-1}(1-A /(2 \pi))$. The formula was derived from the surface area of the spherical cap. The eccentricity of the receptive field was calculated as the geodesic distance between the center of the fitted function and the center of gaze.

The regression lines in Figure 9 assumed that the diameter of the receptive field is related to eccentricity by a power function (Derrington and Lennie, 1984): diameter $=E^{\wedge}(k \times$ eccentricity $+c)$.

In Figures 4-6, the spherical coordinates are visualized in the 2D plane using the area preserving Lambert projection.

The size of the scotoma and percentage of V1 lesioned. The width and length of the scotomas were estimated by fitting 5-parameter FisherBingham distributions to the scotoma boundaries (Table 1). The percentages of $\mathrm{V} 1$ that were lesioned were estimated by projecting the coordinates of the scotoma boundaries to the 3D retinotopic map template in Chaplin et al. (2013) and calculating the ratio between the surface area of the representation of the scotoma and the surface area of the entire $\mathrm{V} 1$.

Latency. Peristimulus time histograms (PSTHs) were calculated from responses to $100-200$ flashes of a square stimulus covering the entire receptive field (see Figs. 7, 8). To estimate the response latency, the PSTH was modeled as generated by a two-stage Poisson process, where the latency was the change-point of the process, using the maximal likelihood method described by Friedman and Priebe (1998). The report of latencies does not include units with OFF responses.

Experimental design and statistical analysis. All statistical tests were performed in R ( $\mathrm{R}$ Core Team, 2013). The nonparametric Kruskal-Wallis test was used to determine whether the median values of the dependent variables (response strength, response latency) were the same across two or three factors (age group or layer of the sample). Quantile regression (see Fig. 9) was performed with the quantreg package. The cramer package was used to perform the nonparametric two-sample Cramér test (Baringhaus and Franz, 2004) to assess whether two sets of bivariate data were sampled from the same distribution.

Histology. Histological analysis was performed to examine the extent of the V1 lesions, to establish the boundaries of MT, to estimate the lesion projection zone in the LGN, and to reconstruct the recording sites. At the end of the experiment, the animal was given a lethal dose of sodium pentobarbitone $(100 \mathrm{mg} / \mathrm{kg})$ and perfused with $0.9 \%$ saline, followed by $4 \%$ PFA in $0.1 \mathrm{~m}$ phosphate buffer, $\mathrm{pH}$ 7.4. The brain was postfixed $(24 \mathrm{~h})$, cryoprotected with increasing concentrations of sucrose, and then sectioned into $40 \mu \mathrm{m}$ coronal slices. Alternate series were stained for Nissl substance, myelin (Gallyas, 1979), and cytochrome oxidase (Silverman and Tootell, 1987). In some cases (WA6, WG3, WG4), NeuN immunohistochemistry was performed as described by Atapour et al. (2017). The volume of the LGN (Table 2) was estimated using the method described in Atapour et al. (2017).

\section{Results}

We performed partial lesions of $\mathrm{V} 1$ on the left hemispheres of 6 marmosets (Table 1). Marmosets reach sexual maturity in $\sim 18$ months (Chandolia et al., 2006) and have average life spans of 13 years in captivity (Nishijima et al., 2012). Two of the animals (the infant group) received lesions in the early postnatal period (second and sixth weeks), during which the thalamus and the visual cortex are still undergoing rapid developmental changes (Fritschy and Garey, 1986a,b; Missler et al., 1993a,b; Bourne and Rosa, 2006; Mundinano et al., 2015). Two animals received lesions as young adults ( $2-3$ years; the adult group), and two others in old age ( 9 and 10 years; the late-life group). The duration of the survival times ( $>1.5$ years; Table 1$)$ was sufficient to ensure that the cell death in LGN had stabilized (Atapour et al., 2017). In all cases except W6E, we verified that the lesions did not abolish visual responses in the extrastriate cortex, as evidenced by the fact
A
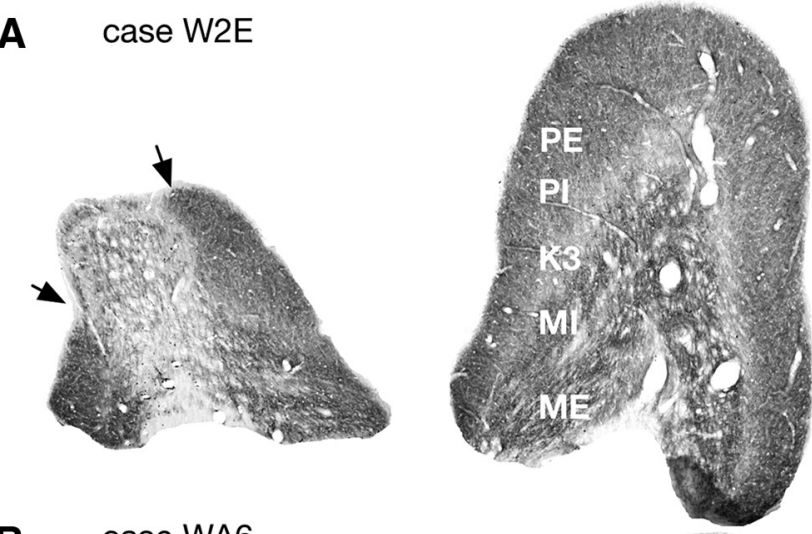

B

case WA6
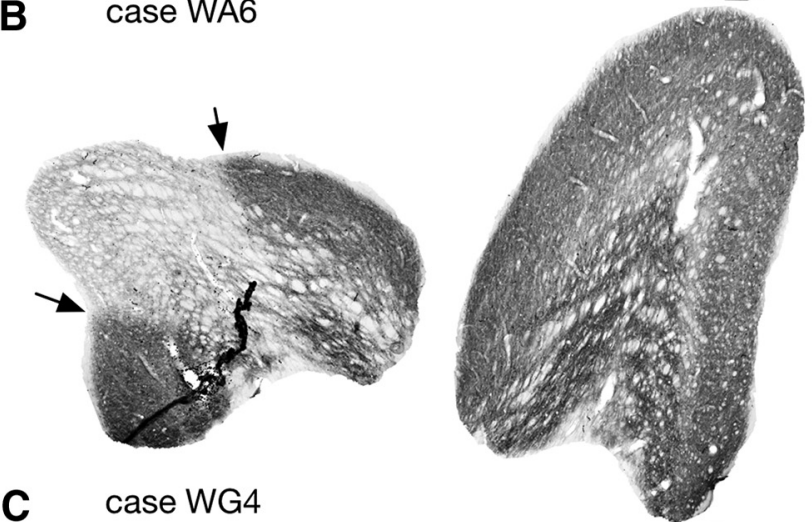

C case WG4

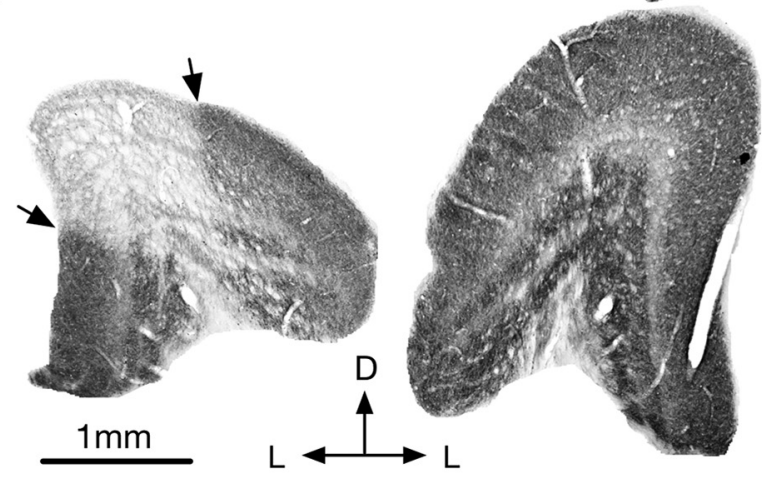

D case W6E

E

case WA5
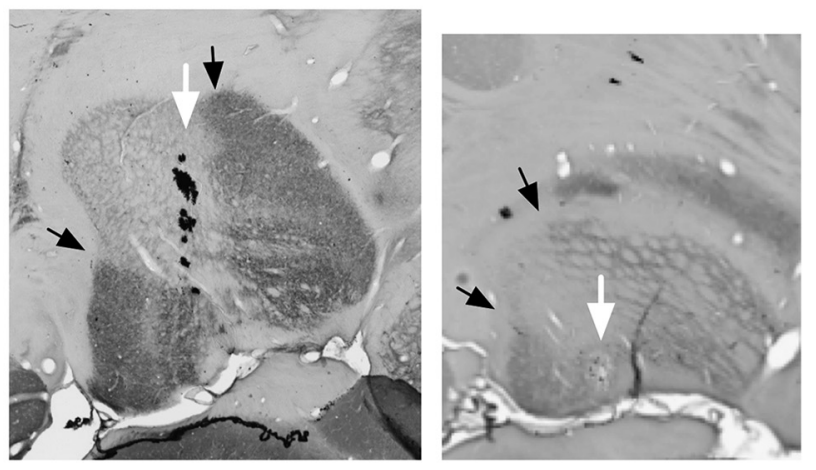

Figure 2. A-C, Coronal histological sections (processed for cytochrome oxidase) from 3 cases (1 case from each lesion group). Left, The LGN ipsilateral to the V1 lesion. Right, The contralateral LGN. Sections were chosen where the size of the LGN was maximal. $\boldsymbol{D}$, White arrow indicates an electrode tract through indicates an electrode tract through the LGN. $\boldsymbol{E}$, White arrow indicates an electrolytic lesion made during the recording. Black arrows indicate the boundaries of the lesion projection zones. D, Dorsal; L, lateral; PE, external parvocellular layer; $\mathrm{PI}$, internal parvocellular layer; $\mathrm{MI}$, internal magnocellular layer; $\mathrm{ME}$, external magnocellular layer. 
A

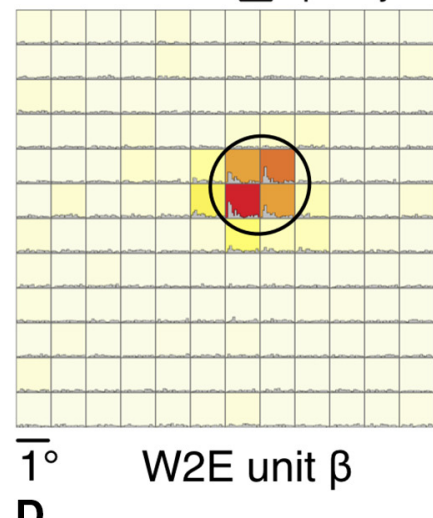

D

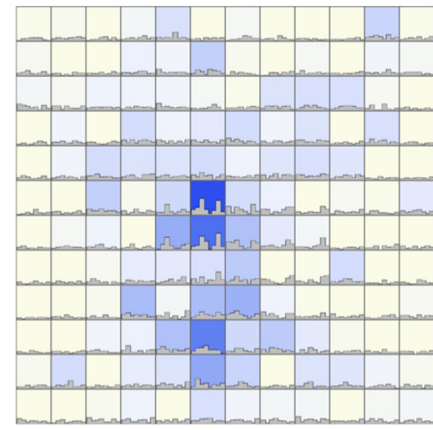

$\overline{1.5^{\circ}}$ WA5 unit e
B
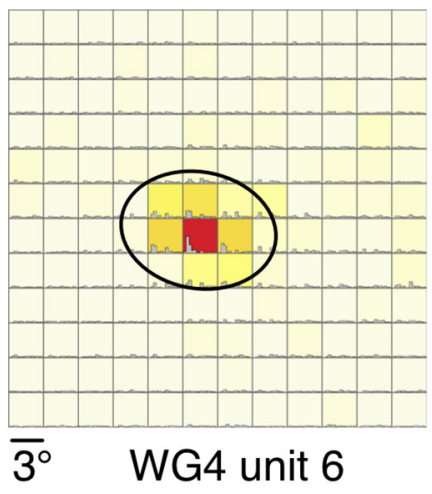

E

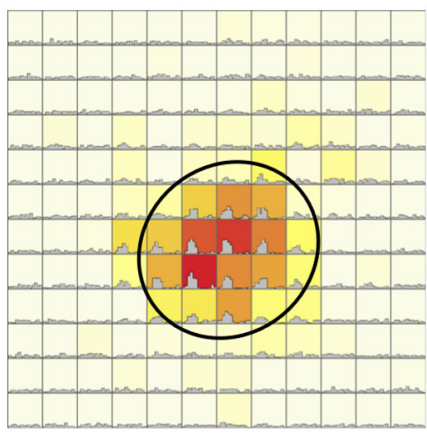

$\overline{2^{\circ}} \quad$ WA6 unit $\mathrm{C}$
C

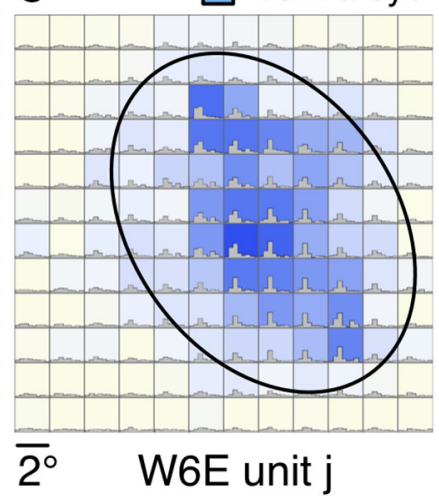

$\mathbf{F}$

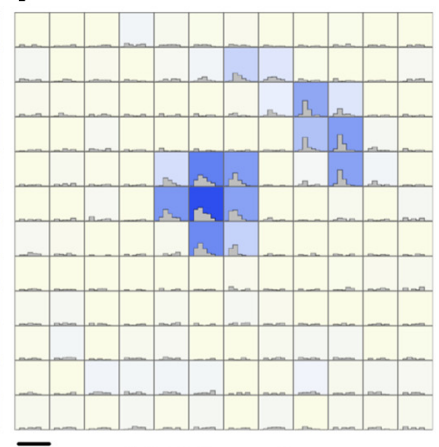

\section{$\overline{1.5}^{\circ}$ WA5 unit $g$}

Figure 3. Examples of quantitatively mapped receptive fields of $L G N$ neurons. Except for $F$, the receptive fields were inside the physiological scotomas. Color scale represents above-spontaneous firing rates in response to a flashing square stimulus displayed at the $12 \times 12$ locations. Red-yellow color scale $(\boldsymbol{A}, \boldsymbol{B}, \boldsymbol{E})$ represents stimulation through the ipsilateral eye. Blue color scale $(\boldsymbol{C}, \boldsymbol{D}, \boldsymbol{F})$ represents stimulation through the contralateral eye. The PSTHs are also plotted for each of the $12 \times 12$ locations. Oval-shaped contours indicate the estimated boundaries of the receptive fields. $\boldsymbol{E}$, The map was measured with a flashing blue square because a flashing white square was not able to elicit reliable responses. All other receptive fields were mapped with a flashing white square. The visual field coordinates of the centers of each panel are as follows: $\boldsymbol{A},\left(9.0^{\circ}, 1.5^{\circ}\right) ; \boldsymbol{B},\left(17.8^{\circ}, 3.4^{\circ}\right) ; \boldsymbol{C},\left(27.8^{\circ}, 8.7^{\circ}\right) ; \boldsymbol{D},\left(49.4^{\circ}, 17^{\circ}\right) ; \boldsymbol{E},\left(16.0^{\circ}, 12.0^{\circ}\right) ; \boldsymbol{F},\left(61.0^{\circ}, 29.6^{\circ}\right)$.

that some of the receptive fields of neurons in area MT were found within the parts of the visual field affected by the lesions (the scotomas).

\section{Estimation of the scotomas and the lesion projection zones in the LGN}

The lesions ablated a large portion of V1 in the left hemisphere, and in some cases small parts of adjacent area V2, while leaving parts of V1 in the rostral calcarine sulcus intact (Rosa et al., 2000; Yu et al., 2013). This resulted in a large region in the right visual field without representation in V1, which will be referred to as the physiological scotoma. For each case, we mapped the receptive fields of neurons in V1 close to the edge of lesions and used these to estimate the extent of the physiological scotomas as the gap in the visual field representation (Fig. 1). The sizes and the geometry of the physiological scotomas were consistent with the retinotopy of normal marmoset V1 (Fritsches and Rosa, 1996; Chaplin et al., 2013). Based on the size of the physiological scotoma, we estimated that between $71 \%$ and $93 \%$ of the left V1 were ablated (Table 1).

The most salient anatomical effect of V1 lesions is a marked reduction in the volume of the LGN (Fig. 2). The ratios of the volume of the LGN ipsilateral and contralateral to the V1 lesions varied between $47.5 \%$ and $61.9 \%$ (Table 2), and there was no significant difference among animals in the three age groups (Kruskal-Wallis $\mathrm{H}=1.4286, p=0.677553)$. In cytochrome oxidase-stained sections, the lesion projection zones (i.e., the parts of the LGN that underwent retrograde transneuronal degeneration following V1 lesions) could be readily identified as
Table 3. The number of electrode penetrations made, and the number of quantified receptive fields that were inside, on the boundary, and outside the physiological scotoma in each case

\begin{tabular}{|c|c|c|c|c|c|c|}
\hline Case & $\begin{array}{l}\text { No. of } \\
\text { tracks }\end{array}$ & $\begin{array}{l}\text { No. of tracks } \\
\text { without } \\
\text { parvocellular } \\
\text { units }\end{array}$ & $\begin{array}{l}\text { No. of } \\
\text { units }\end{array}$ & $\begin{array}{l}\text { No. of units } \\
\text { in scotoma }\end{array}$ & $\begin{array}{l}\text { No. of units } \\
\text { on scotoma } \\
\text { boundary }\end{array}$ & $\begin{array}{l}\text { No. of units } \\
\text { outside } \\
\text { scotoma }\end{array}$ \\
\hline W2E & 4 & 4 & 42 & 41 & 0 & 1 \\
\hline W6E & 3 & 1 & 42 & 16 & 2 & 24 \\
\hline WA5 & 6 & 0 & 65 & 56 & 2 & 6 \\
\hline WA6 & 5 & 1 & 84 & 45 & 8 & 31 \\
\hline WG3 & 4 & 1 & 24 & 24 & 0 & 0 \\
\hline WG4 & 3 & 1 & 47 & 29 & 2 & 16 \\
\hline
\end{tabular}

pale-staining, wedge-shaped sectors (Fig. 2A-C), which followed the canonical retinotopy of the marmoset LGN (White et al., 1998). This clear transition in levels of metabolic activity allowed a precise correlation between the locations of recording sites, reconstructed using histological signs of capillary bleeding, gliosis, and electrolytic lesions (Fig. 2D), and the sectors of the LGN directly affected by the lesions.

\section{Neurons in the lesion projection zones were activated by} visual stimulation

In all 6 cases, we were able to record many neurons that responded to small flashing stimuli presented inside the physiological scotomas. Figure $3 A-E$ illustrates examples of receptive fields 
A case W2E

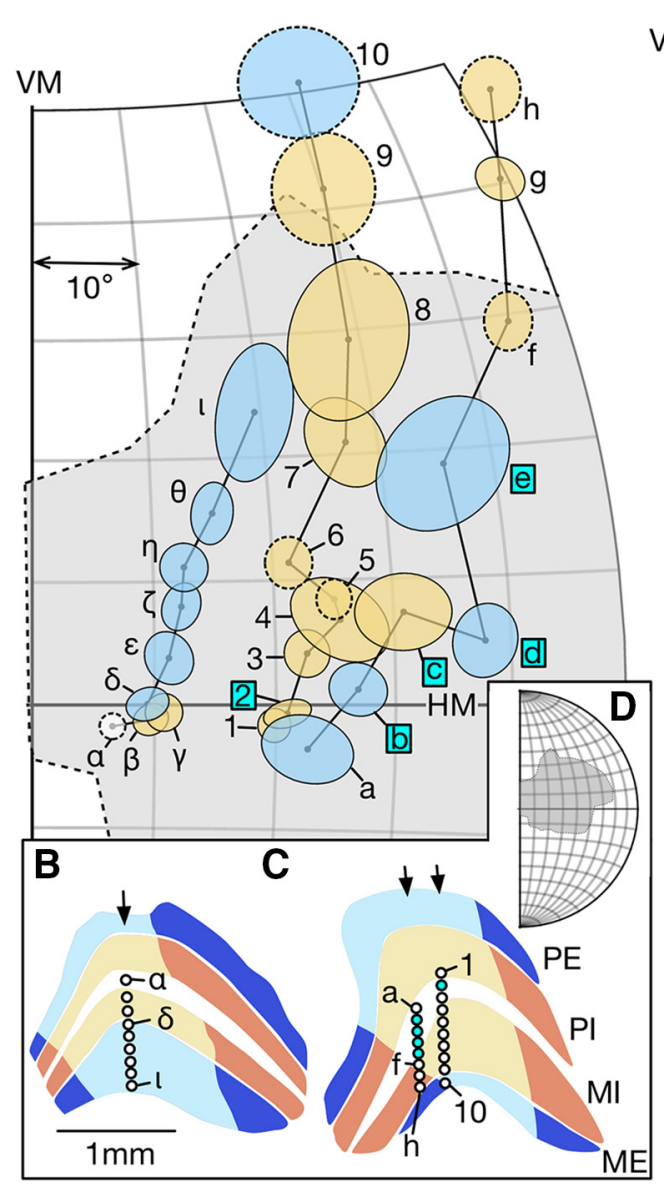

E case W6E

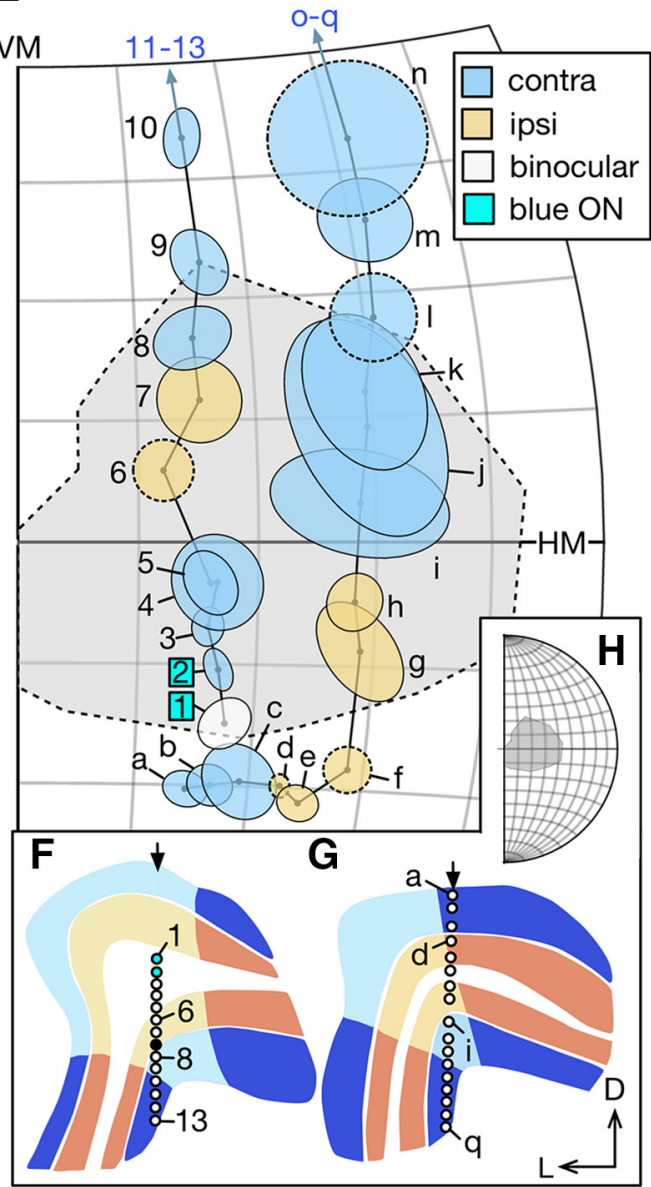

Figure 4. Representative progressions of receptive fields of $L G N$ neurons sampled during vertical electrode penetrations, in the infant group. $\boldsymbol{A}$, Receptive fields encountered in three penetrations in Case W2E. Ovals with solid boundaries represent receptive fields quantitatively mapped. Ovals with dashed boundaries represent receptive fields qualitatively mapped with a manually operated stimulus. Receptive fields driven only by the contralateral (ipsilateral) eye are shaded in blue (orange). Unit $\alpha$ was binocular. Unit 2 and b-e, indicated with labels in cyan-colored boxes, mapped with a flashing blue square. Others were mapped with a flashing white square. Dashed region shaded in light gray represents the estimated physiological scotoma. $\boldsymbol{B}, \boldsymbol{C}$, Tracings of coronal sections of the LGN. Layers shaded in blue represent contralateral-eye dominated layers (layer PE and ME). Layers shaded in orange represent ipsilateral-eye dominated layers (layer PI and MI). Regions shaded in lighter colors represent the lesion projection zones. The section illustrated in B was $0.6 \mathrm{~mm}$ caudal to the one illustrated in $C$. The penetration site for units a-h was slightly more rostral ( $\sim 0.2 \mathrm{~mm}$ ) to that for units 1-10. Arrows indicate the surface locations of the electrode penetrations. Circles represent the recording sites associated with the receptive fields in $\boldsymbol{A}$. Circle filled with black represents a site where no stimulus-evoked responses could be observed. Circles shaded in cyan are associated with receptive fields mapped with blue light in $\boldsymbol{A}$. $\boldsymbol{D}$, A larger view of the visual space plotted in $\boldsymbol{A}$, showing the entire extent of the physiological scotoma. $\boldsymbol{E}$, Receptive fields encountered during two penetrations in Case W6E, plotted in the same format as in Case W2E. Receptive fields (units 11-13 and 0-q) far outside the physiological scotoma are omitted for brevity. $\boldsymbol{F}, \mathbf{G}$, The section illustrated in $\boldsymbol{F}$ was $0.4 \mathrm{~mm}$ caudal to the one in $\boldsymbol{G}$. $\boldsymbol{H}$, The extent of the scotoma in case W6E. VM, Vertical meridian; HM, horizontal meridian; D, dorsal; L, lateral; PE, external parvocellular layer; PI, internal parvocellular layer; $M I$, internal magnocellular layer; ME, external magnocellular layer.

of LGN neurons that were quantitatively mapped inside the physiological scotomas. In this and subsequent figures, LGN receptive fields obtained through stimulation of the contralateral eye are illustrated using a blue color scale, and those obtained through stimulation of the ipsilateral eye are plotted using a yellow-red color scale. Whereas many of the receptive fields shown in Figure 3 did not deviate from the expected nearcircular geometry of LGN receptive fields, some were unusually large and elongated (e.g., Fig. 3C), and others appeared diffuse, despite the existence of a clearly defined central responsive region (Fig. 3D). Finally, in one case (Fig. $3 F$ ), the receptive field appeared to have two spatially distinct components, separated by a gap. This receptive field was estimated to be just outside the scotoma in a young adult marmoset (Case WA5), suggesting that some neurons near the boundary of the anatomically defined lesion projection zones may undergo plastic changes in response to the lesions.

\section{Orderly retinotopy was observed inside the lesion projection zones}

In each case, we made 3-6 electrode penetrations through the depth of the LGN (Table 3). Examples of receptive field sequences sampled in vertical penetrations through the LGN are illustrated in Figures 4-6 for the three age groups. In almost all penetrations, we were able map receptive fields at closely spaced $(\sim 100 \mu \mathrm{m})$ intervals across the LGN, although at some sites we failed to observe evoked responses driven by either of the eyes (Figs. 4-6, bottom, black circles). Case WG3, an animal with lesions introduced late in life (Fig. 6A-C), was the only case with an extended region $(400-500 \mu \mathrm{m})$ in the lesion projection zone where no evoked responses could be found (Fig. 6C).

The progressions of receptive fields were predictable, and consistent with the known retinotopy of marmoset LGN. For example, in each penetration, as the electrode went deeper, receptive fields moved from the lower visual field to the upper visual field 


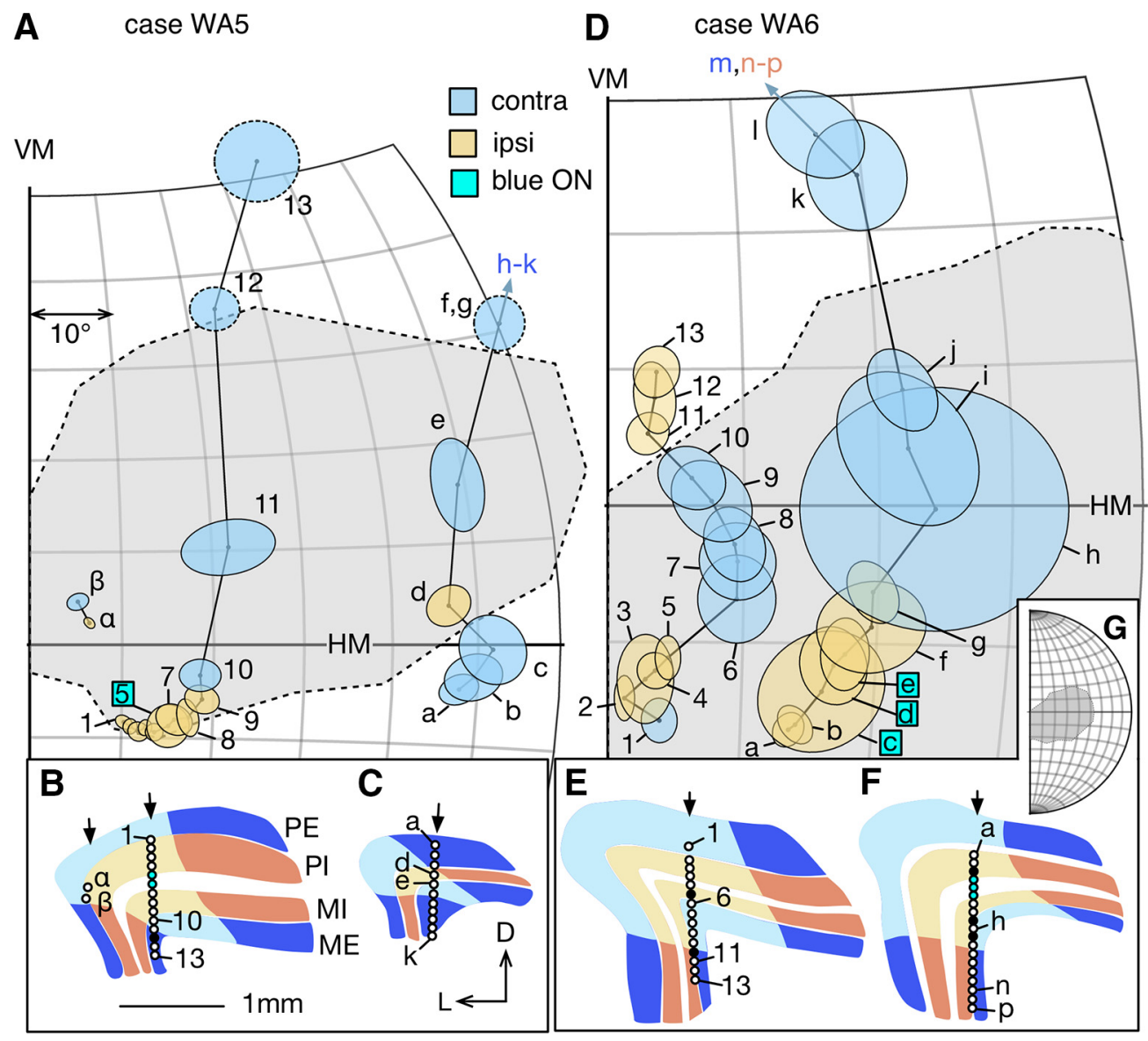

Figure 5. $A, D$, Progression of receptive fields of $L G N$ neurons sampled during vertical electrode penetrations in the adult group. The format is the same as in Figure 4 . Locations of the recording sites are indicated in panels $\boldsymbol{B}, \boldsymbol{C}$ (case WA5) and $\boldsymbol{E}, \boldsymbol{F}$ (case WA6). In case WA5, the sections illustrated in $\boldsymbol{B}$ was $0.96 \mathrm{~mm}$ caudal to the one in $\boldsymbol{C}$. In case WA6, the section illustrated in $\boldsymbol{E}$ was $0.48 \mathrm{~mm}$ caudal to the one in $\boldsymbol{F}$. During the penetration illustrated in $\boldsymbol{E}$, recording stopped at receptive field 13 without through the rest of the LGN. $\boldsymbol{G}$, The relationship of the scotoma of WA6 to the visual hemifield.

(White et al., 1998). Moreover, caudal penetrations resulted in receptive fields closer to the fovea, in comparison with more rostral penetrations (compare, for example, receptive fields $\alpha-\iota$ in Case W2E, with receptive fields $1-10$ and a-h; Fig. 4). In many cases (e.g., $\alpha-\iota$ in Fig. 4A; 1-20 in Fig. 6D), the movements of receptive fields appeared to form a nearly continuous sequence across the physiological scotomas. However, in other penetrations, there were noticeable "jumps" in receptive field location. For example, in Figure 4A, the receptive fields of units 6 and 7, and those of units $\mathrm{d}$ and e were separated by $>10^{\circ}$, although the recording sites were only $\sim 100 \mu \mathrm{m}$ apart. These observations suggest that the continuous retinotopy of the normal LGN could be locally disrupted, resulting in potential gaps in the representation of the visual field.

Only in one penetration (unit 1-13 in WA5; Fig. 5A) did we observe a more significant deviation from the canonical retinotopy of marmoset LGN. For most of the units in this penetration (1-10), the receptive fields clustered at the edge of the physiological scotoma, staying close to the boundary but still moving in a centroperipheral direction. At unit 11, the receptive field moved suddenly to the center of the physiological scotoma, and then, following an unresponsive site, the sequence jumped to the far peripheral edge of the scotoma (unit 12). This trajectory was reminiscent of the reported reorganized retinotopy of area MT, in marmosets with V1-lesioned introduced in early adulthood (Rosa et al., 2000), where the receptive fields of many neurons in the projection zone of MT clustered at the edge of the physiological scotoma. However, the receptive fields in other penetrations in this same animal (e.g., units a-k) were less obviously disrupted.

\section{Eye dominance inside the lesion projection zone was consistent with the normal pattern}

In the normal LGN, neurons in the external parvocellular and magnocellular layers (PE and ME; Fig. $2 A$, right) are driven by the contralateral eye, and neurons in the internal parvocellular and magnocellular layers (PI and MI) are driven by the ipsilateral eye (Spatz, 1978). Koniocellular layers are interleaved between the PE, PI, MI, ME layers, the most prominent being K3, which is sandwiched between PI and MI (Fig. 2A). Koniocellular layers have a mixture of contralateral eye and ipsilateral eye dominated neurons, as well as binocularly activated neurons (Zeater et al., 2015). Almost all the LGN neurons that we recorded could be driven only from one eye, except for the two binocular units encountered in the lesion projection zones of Case W2E (unit $\alpha$; Fig. 4A) and Case W6E (unit 1; Fig. 4E). Because both units were recorded in the K3 layers, they may represent a normal feature of the LGN rather than an effect of lesion-triggered plasticity.

Unlike in the normal LGN, in which the laminar structure is discernible in histological sections (Fig. $2 A-C$, right), the sparse distributions of neurons and neuronal atrophy in the lesion projection zones made precise delineation of the layers difficult (Fig. $2 A-C$, left). However, the fact that the eye dominance pattern of 
A case WG3
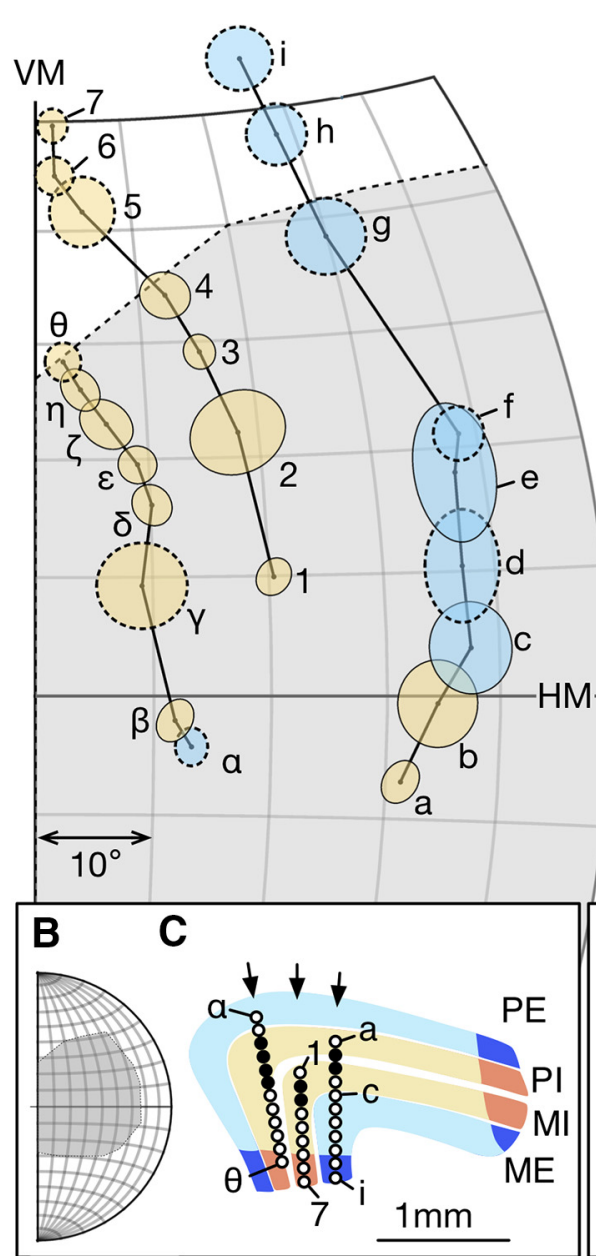

D

case WG4

\section{VM 19,20}

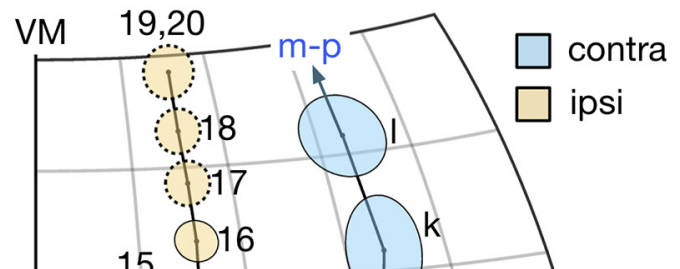

contra
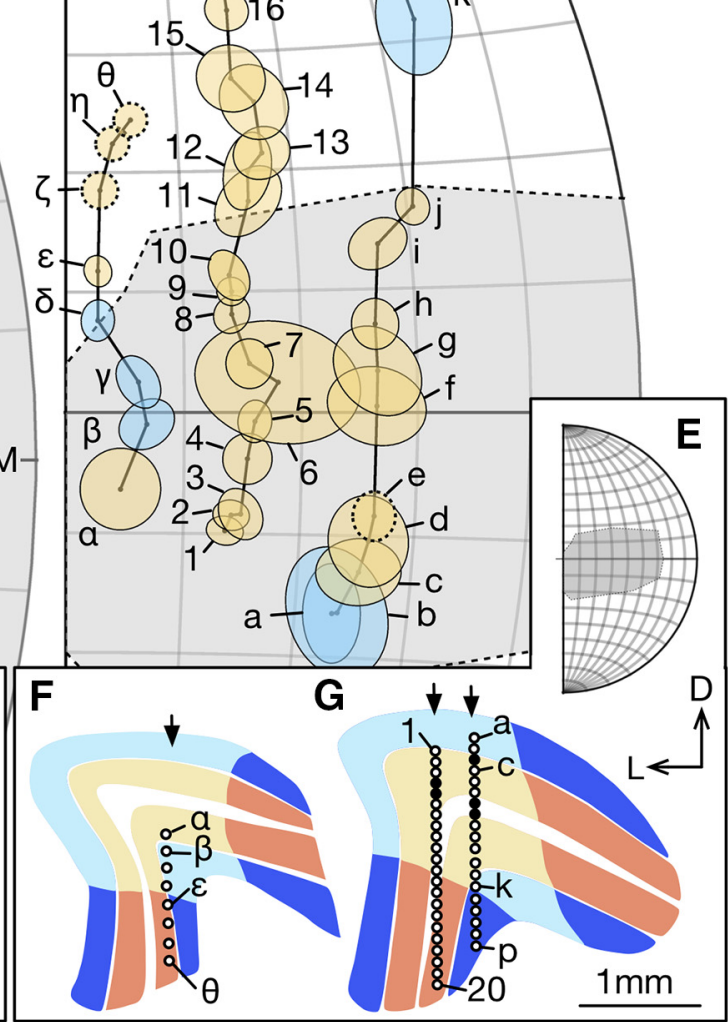

Figure 6. $A, D$, Progression of receptive fields of $L G N$ neurons sampled during vertical electrode penetrations in the late-life group. The format is the same as in Figure 4. Locations of the recording sites are indicated in panels $\mathbf{C}$ (case WG3) and $\boldsymbol{F}, \boldsymbol{G}$ (case WG4). For WG3, the most lateral penetration $(\alpha-\theta)$ was in a section plane $0.16 \mathrm{~mm}$ caudal to the one for the other two penetrations. For WG4, the sections illustrated in $\boldsymbol{F}$ and $\boldsymbol{G}$ were $0.48 \mathrm{~mm}$ apart $(\boldsymbol{F}$ was more caudal).

neurons in the lesion projection zones was clustered strongly suggested the preservation of a laminar structure. Indeed, in all penetrations, the alternation of eye dominance of neurons inside the physiological scotoma was compatible with pattern described in the normal LGN. In Figures 4-6 (bottom), the lamination patterns inside the lesion project zones (the regions shaded in lighter colors) illustrate determinations based on eye dominance, the depth of the recording sites, and the response characteristics of the neurons (see below). In some cases, the patterns of eye dominance were simple. For example, all the receptive fields in penetration 1-7 in Case WG3 (Fig. 6A) and penetration 1-20 in Case WG4 (Fig. 6D) were dominated by the ipsilateral eye because the penetrations were parallel to the layers. In others case, the patterns were more complex. For example, during the penetration 1-13 in Case WA6 (Fig. 5D), eye dominance switched three times. This was consistent with a penetration that began in the PE layer (contralateral eye), crossed the two internal layers (PI and MI; ipsilateral eye), then moved into the ME layer contralateral eye), and finally reentered the MI layer again (Fig. 5E).

\section{Parvocellular layers were often nonresponsive in the lesion} projection zones

The most dorsal layer of the normal LGN (PE) is dominated by the contralateral eye. However, in 13 of the 25 penetrations in our dataset, the first LGN receptive fields encountered were dominated by the ipsilateral eye (e.g., unit 1 in Fig. $4 A$, unit 1 in Fig. $5 A$, unit a in Fig. $5 D$, unit 1 in Fig. $6 A$, and unit $\alpha$ in Fig. $6 D$ ), or binocular (units $\alpha$ in Fig. $4 A$ and unit 1 in Fig. $4 E$ ). In these penetrations, neurons in the PE layer were either nonresponsive or responded too weakly to allow the receptive fields to be determined.

Case $\mathrm{W} 2 \mathrm{E}$ in the infant group was a representative example. In each the three penetrations illustrated (Fig. $4 B, C$ ), the length of the region in which receptive fields could be mapped accounted only for a proportion $(\sim 60 \%)$ of the length of the electrode track histologically determined to be within the LGN. The presence of a binocular unit $(\alpha)$ and other units (units 2 and b-e) that were most strongly activated by blue light (see Neurons in the lesion projection zone had diverse response characteristics) further indicates that the receptive field sequences started in the K3 layer. A fourth penetration (not illustrated in Fig. 4) in this case also started with a unit dominated by the ipsilateral eye, which could only be mapped with a blue stimulus, suggesting the likelihood that in this case, the parvocellular layers in the lesion projection zone were nonresponsive.

Even when a penetration first encountered a cluster of contralateral eye dominated neurons (e.g., penetration a-h in Case W2E), they were not necessarily in the PE layer, given that the K3 


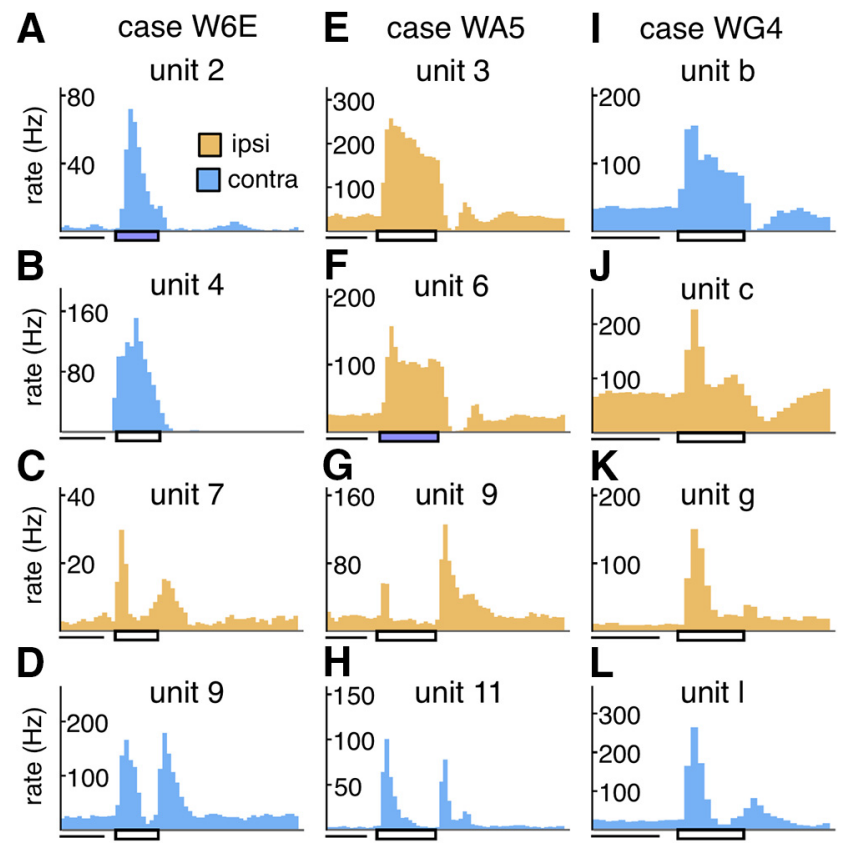

Figure 7. The PSTHs of representative units recorded in lesion projection zones. The color of the histogram represents the eye dominance of the unit. Light blue represents contralateral eye. Orange represents ipsilateral eye. Horizontal rectangle underneath the $x$ axes represents the time interval during which the stimulus was turned on. White rectangle represents a white stimulus. Blue rectangle represents that a blue stimulus was used. The PSTHs in each column are from units sampled in the same penetration, for 1 case in each of the three groups $(\boldsymbol{A}-\boldsymbol{D}$ : case W6E; $\boldsymbol{E}-\boldsymbol{H}$ : case WA5; $\boldsymbol{I} \boldsymbol{- L}$ : case WG4). The receptive field associated with each unit can be identified in Figures 4-6 by the unit label above each PSTH.
A
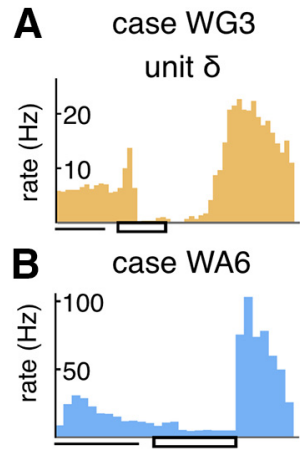

C case W2E
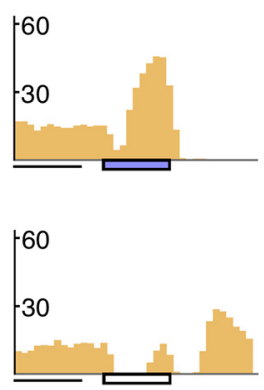
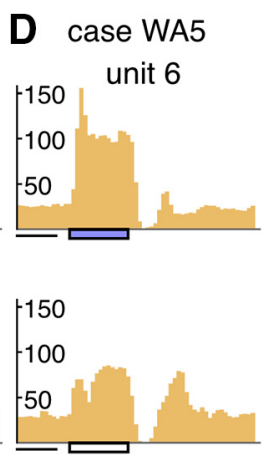

Figure 8. Additional examples of PSTHs of units recorded in the lesion projection zone. The format is the same as in Figure 7. $\boldsymbol{A}, \boldsymbol{B}$, Examples of OFF responses. $\boldsymbol{C}, \boldsymbol{D}$, The response patterns of the same units to a flashing stimulus with the blue filter (top subpanel) and without it (bottom subpanel). $\boldsymbol{B}-\boldsymbol{D}$, The units do not have corresponding receptive fields in Figure 4-6 because they were not sampled in the penetrations illustrated.

layer also contains a population of contra-eye dominated neurons (Zeater et al., 2015). Among 25 electrode penetrations in our dataset, 8 went through the parvocellular layers without encountering clear responses (Table 3). Case W2E (the animal that received the lesion at the youngest stage) was the only case where parvocellular layers were nonresponsive in all penetrations.

\section{Neurons in the lesion projection zone had diverse response characteristics}

Units recorded within the LGN lesion projection zones exhibited a diverse range of response characteristics. Representative PSTHs are illustrated in Figures 7 and 8. Although most of the units responded to the onset of stimuli, a subset responded most
Table 4. The number of quantified receptive fields categorized by the layers that they were sampled in, eye dominance, and response characteristics

\begin{tabular}{|c|c|c|c|c|c|c|c|c|c|}
\hline Case & $\begin{array}{l}\text { No. of } \\
\text { "blue-ON" } \\
\text { units }\end{array}$ & $\begin{array}{l}\text { No. of } \\
\text { OFF } \\
\text { units }\end{array}$ & $\begin{array}{l}\text { No. of } \\
\text { ipsilateral } \\
\text { eye units }\end{array}$ & $\begin{array}{l}\text { No. of } \\
\text { contralateral } \\
\text { eye units }\end{array}$ & $\begin{array}{l}\text { No. of } \\
\text { units } \\
\text { in PE }\end{array}$ & $\begin{array}{l}\text { No. of } \\
\text { units } \\
\text { in PI }\end{array}$ & $\begin{array}{l}\text { No. of } \\
\text { units } \\
\text { in K3 }\end{array}$ & $\begin{array}{l}\text { No. of } \\
\text { units } \\
\text { in MI }\end{array}$ & $\begin{array}{l}\text { No. of } \\
\text { units } \\
\text { in ME }\end{array}$ \\
\hline W2E & 9 & 1 & 25 & 17 & 0 & 0 & 11 & 18 & 13 \\
\hline W6E & 1 & 1 & 7 & 35 & 10 & 1 & 4 & 6 & 21 \\
\hline WA5 & 2 & 1 & 28 & 33 & 23 & 22 & 2 & 5 & 13 \\
\hline WA6 & 6 & 3 & 31 & 53 & 25 & 19 & 6 & 8 & 26 \\
\hline WG3 & 0 & 1 & 18 & 6 & 4 & 12 & 0 & 6 & 2 \\
\hline WG4 & 0 & 6 & 34 & 13 & 4 & 17 & 1 & 16 & 9 \\
\hline
\end{tabular}

strongly to their offset (e.g., Fig. 8A,B). We documented 13 of 304 units of this type (Table 4). In addition, we encountered neurons showing transient responses to both the onset and the offset of the stimulus (e.g., Fig. 7C, D, G,H).

Transient and sustained response types could also be distinguished. Figure 7E, I illustrates the PSTHs of representative neurons exhibiting elevated firing rates throughout the duration of the stimulus, both of which were recorded in putative parvocellular layers. Those illustrated in Figure $7 K, L$, on the other hand, responded transiently to the onset of the stimulus. These transient responses were primarily observed in deep (putative magnocellular) layers.

In some penetrations, we encountered units that responded weakly when stimulated by broadband white stimuli produced by the projector but responded briskly when a Kodak Wratten 47B blue filter was used to eliminate wavelengths longer than $500 \mathrm{~nm}$. The PSTHs two such unit are shown in Figure $8 C, D$. The responses of the unit shown in Figure $8 C$, in particular, were suppressed by the white light but produced robust responses when stimulated by the blue light. We documented 18 of 211 units of this type in the degenerated zone, in both the infant group and adult groups, but could not identify them in our sample of latelife animals (Table 4). They were found in the middle of the degenerated zone, typically in the transition between zones where transient and sustained responses were recorded. Because the Wratten 47B dark blue filter has a transmission spectrum that closely resembles the sensitivity function of the blue cone in the retina (peak transmission at $430 \mathrm{~nm}$ ), it is likely these neurons are "blue-ON" neurons in the koniocellular K3 layer (White et al., 1998; Roy et al., 2009).

\section{Many receptive fields inside the physiological scotomas were larger than expected}

Some of the LGN receptive fields inside the physiological scotomas illustrated in Figures 4-6 appeared to be unusually large (diameter $>10^{\circ}$ ). To determine whether there was a systematic difference in receptive field size for neurons sampled inside and outside the lesion projection zones, we plotted the relationship between the eccentricity and the diameter of the receptive field in Figure 9.

Receptive fields outside the physiological scotomas were presumably minimally affected by the V1 lesions. Pooling data from all 6 cases, the distributions of receptive field diameters as functions of eccentricity are plotted in Figure $9 A$ for units sampled in putative parvocellular layers, and in Figure $9 B$ for units sampled in putative magnocellular layers. Although the nonparametric bivariate Cramér test (cramer package in R; Baringhaus and Franz, 2004) did not detect a significant difference between the two distributions (Cramér statistics $=11.74049, p=0.2857143$ ), the median values, as illustrated by the 0.5 quantile regression 
lines in Figure 9A (inset), suggest that magnocellular units tend to have larger receptive fields than the parvocellular units, as reported in the macaque LGN (Derrington and Lennie, 1984).

Quantile regression was used to estimate the receptive field diameters that accounted for $15 \%$ and $85 \%(0.15$ and 0.85 quantile) of the data shown in Figure 9A, $B$, assuming that the relationship followed a power function (Derrington and Lennie, 1984). The fitted functions are plotted in Figure $9 A-D$ as dashed lines. For receptive fields inside or at the boundaries of the physiological scotomas, the diameters for parvocellular units and magnocellular units are plotted in Figure $9 C, D$. The distributions were significantly different from those plotted in Figure 9A, $B$ (parvocellular: Cramér statistic $=87.57337, p=$ 0.0 ; magnocellular: Cramér statistic $=$ 109.601, $p=0.0$ ).

The receptive field diameters of a small population $(N=24)$ of units sampled in the putative $\mathrm{K} 3$ layer are also illustrated in Figure $9 D$. Although the range of diameters overlapped significantly with those of magnocellular units, the Cramér test suggested a significant difference in the distributions (Cramér statistic $=17.40669, p=$ 0.03796204 ). The median values (Fig. $9 C$, inset) indicate that magnocellular units with receptive fields within the physiological scotomas tended to have larger receptive fields than parvocellular units in the corresponding sectors of the LGN.

Figure $9 C, D$ suggests that many receptive fields inside or on the boundary of the physiological scotomas were $>85 \%$ of the receptive fields outside. When data from all cases were pooled, the receptive fields of 13 of 99 (13.\%) parvocellular units and 44 of 102 magnocellular units (43.3\%) were larger than the 0.85 quantile regression lines estimated with receptive fields outside the scotomas. The percentages were significantly different $\left(\chi^{2}=\right.$ $20.812, \mathrm{df}=1, p=5.067 \mathrm{e}-06$ ). Because no putative $\mathrm{K} 3$ units were found outside the physiological scotomas, potential changes in receptive field diameter could not be estimated. In summary, although larger-than-expected receptive fields were found throughout the depth of the lesion projection zone, this was most prominent in the magnocellular layers. Figure 10 highlights receptive fields larger than the 0.85 quantile thresholds in each case. Such receptive fields were observed in all cases, were more likely to be found in the middle of the physiological scotomas, and appeared to occur in clusters. Although Figure $9 D$ also indicates the possibility of magnocellular neurons with receptive fields smaller than the expected range, these were either similar in size to some of those observed outside the scotomas (Fig. 9B) or had low eccentricities (for which we had no comparable sample among the units recorded outside the scotomas).

To examine whether the numbers of unexpectedly large receptive fields were dependent on the age at which the lesion occurred, we calculated the numbers of receptive fields inside or on
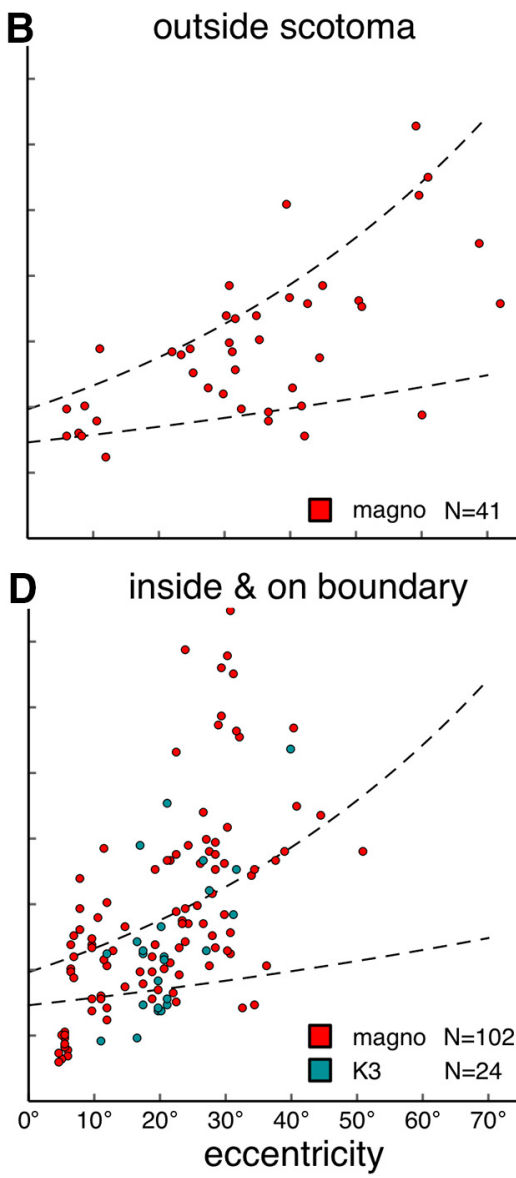

eccentricity

Figure 9. Receptive field diameters as functions of eccentricity. The diameter was calculated as the diameter of a circular receptive field, whose surface area was matched to the surface area of the fitted oval-shaped receptive field (see Materials and boundaries of the physiological scotomas. A small population of units sampled in the putative K3 layer is also plotted in $\boldsymbol{D}$ (as blue in contrast to the red dots representing magnocellular units). Dashed lines are the same 0.15 quantile and the 0.85 quantile regression lines plotted in $\boldsymbol{A}$ and $\boldsymbol{B}$. C, Inset, Regression lines for the median values. Green represents parvocellular units. Red represents magnocellular units. Blue represents $\mathrm{K} 3$ units.

the boundaries of the physiological scotomas that were larger than the 0.85 quantile thresholds. For magnocellular units, the percentages of units with receptive field size larger than the threshold for the infant, adult, and late-life groups were $45.5 \%$ (20 of 44), 43.9\% (18 of 41), and 35.3\% (6 of 17), respectively $\left(\chi^{2}=0.53244, \mathrm{df}=2, p=0.7663\right)$. No parvocellular units were found inside or on the boundaries of the scotomas in the infantlesioned group, but for the adult and late-life groups, the percentages of units with unexpectedly large receptive fields were also not significantly different $\left(\chi^{2}=2.7447, \mathrm{df}=1, p=0.09758\right)$. As stated above, because the expected diameter for K3 units could not be estimated, a similar analysis could not be conducted.

Units within the lesion projection zones had robust responses The response strength of LGN units was estimated as the maximal firing rate above the spontaneous activity. Figure 11 illustrates the distributions of response strength. Pooling data from all 6 cases, the median response strength were $82.8,67.8$, and $82.5 \mathrm{~Hz}$ for the parvocellular, K3, and magnocellular units, respectively. These distributions were not significantly different (Kruskal-Wallis $\mathrm{H}=2.129, p=0.346031$ ). In Figure 11 (left), the distributions 

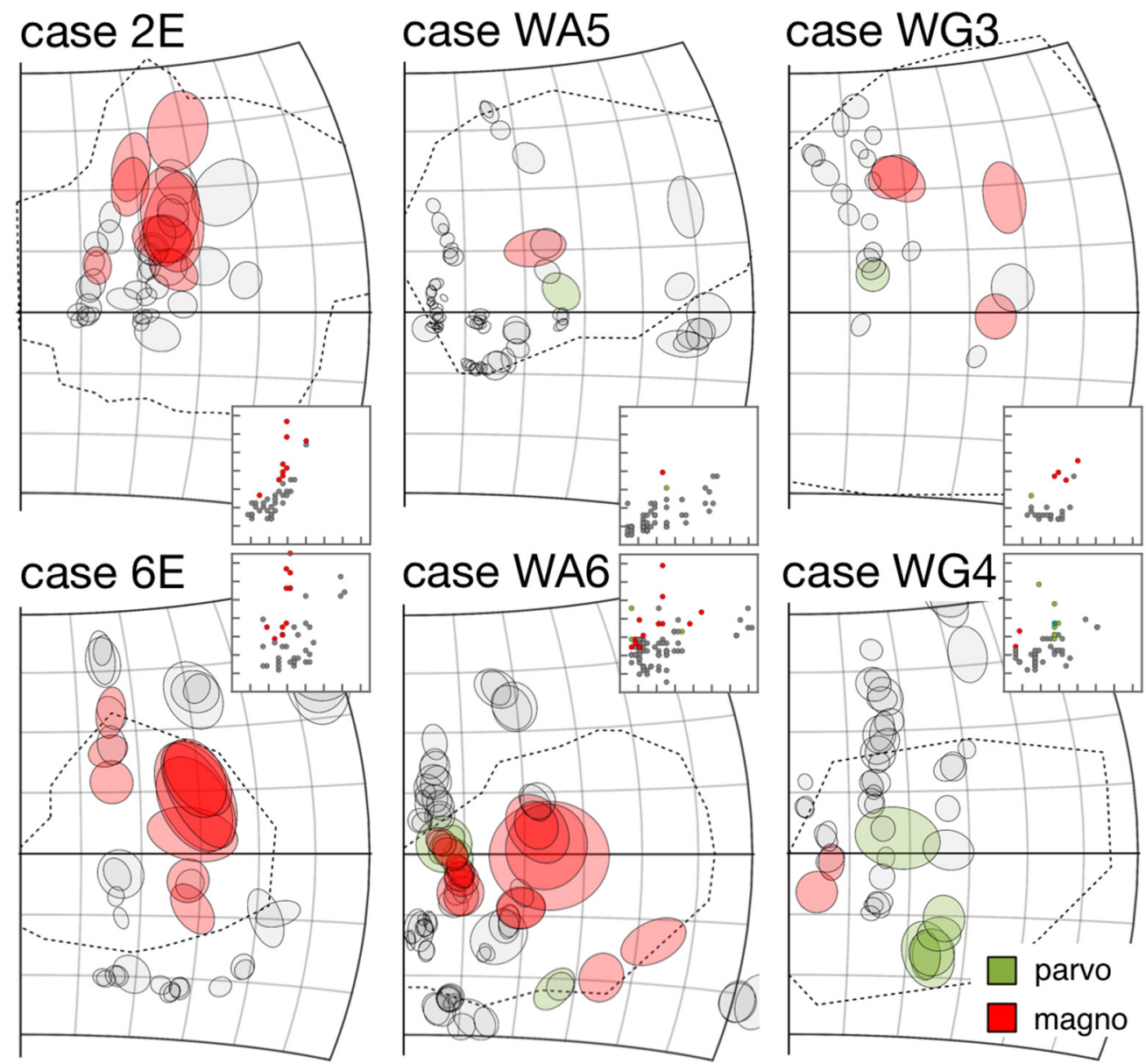

Figure 10. All quantitatively mapped receptive fields, plotted separately for the 6 individual cases. For receptive fields inside or on the boundary of the physiological scotomas, those that were larger than the 0.85 quantile thresholds (Fig. $9 A, B$ ) are shaded in green for parvocellular units and red for magnocellular units. Insets, The distributions of receptive field diameters (y axis) against eccentricity ( $x$ axis). The scale is identical to that in Figure $9 A-D$. The receptive fields in the main panels that are shaded in colors are also indicated in the insets using the same color scheme.

were further divided by the locations of the receptive fields relative to the physiological scotomas. For the magnocellular units, the median values of response strength were not significantly different $(80.0 \mathrm{~Hz}$ vs $90.3 \mathrm{~Hz} ; \mathrm{H}=1.88483, p=0.170616)$, but a similar analysis of parvocellular units suggested slightly reduced response strengths inside the scotomas $(72.2 \mathrm{~Hz}$ vs $103.9 \mathrm{~Hz} ; \mathrm{H}=$ $6.4292, p=0.0106971)$. This analysis could not be performed for the $\mathrm{K} 3$ units due to the lack of receptive fields outside the scotomas.

We also compared the response strengths according to age groups, for units with receptive fields inside or on the boundaries of the physiological scotomas (Fig. 11, right). Although significant differences were detected in the parvocellular $(87.8 \mathrm{~Hz}$ for the adult group vs $62.3 \mathrm{~Hz}$ for the late-life group; $\mathrm{H}=4.48092$, $p=0.033576)$ and magnocellular layers (107.8 Hz vs $62.7 \mathrm{~Hz}$ vs $80.6 \mathrm{~Hz}$ for the infant, adult, and late-life groups; $\mathrm{H}=17.8883$, $p=0.0000623422$ ), the differences were subtle.

\section{The response latencies of LGN units were short}

The response patterns of the surviving LGN neurons were consistent under repeated stimulations (Fig. 12, left). Figure 12 (middle) plots the distributions of response latencies, measured with brief (200-300 ms) presentations of a bright stimulus that covered the receptive fields. Pooling data across cases, the median latencies for units in the parvocellular, $\mathrm{K} 3$, and magnocellular layers were 31,32 , and $24 \mathrm{~ms}$, respectively. The difference be- tween the parvocellular and the magnocellular units was significant $(\mathrm{H}=76.105, p=5.36176 \mathrm{e}-21)$, as expected based on previous studies in macaques (Schmolesky et al., 1998). When the latency estimates were sorted by the locations of the receptive fields relative to the boundaries of the physiological scotomas (Fig. 12, middle), the distributions were found to be largely overlapping.

Figure 12 (right) illustrates the distributions of the response latencies estimated for the three age groups. Only units with receptive fields inside or on the boundaries of the physiological scotomas were included in this analysis. For parvocellular units, the median values were not significantly different $(\mathrm{H}=$ $0.00328296, p=0.954655$ ), but for the magnocelular and the $\mathrm{K} 3$ units, the mean latencies in the infant group were slightly shorter than in the other two groups: For the magnocellular units, median values were 22,26 , and $25 \mathrm{~ms}$ for the infant, adult, and late-life groups $(\mathrm{H}=47.4739, p=1.35825 \mathrm{e}-14)$; and for the $\mathrm{K} 3$ units, median values were $28.5,39.0$, and 31.0 $\mathrm{ms}(\mathrm{H}=7.25949, p=0.00439636)$.

We also checked if units with unexpectedly large receptive fields had longer latencies. Because of sample sizes, this analysis was performed only with magnocellular units with receptive fields inside or on the boundaries of the scotomas. Using the 0.85 quantile threshold for receptive field size, we found that the median latencies for units with unexpectedly large receptive fields were in fact slightly shorter, at least in the infant and the adult 
group (infant: $20.5 \mathrm{~ms}$ vs $22 \mathrm{~ms}, \mathrm{H}=$ 5.05204, $p=0.022647$; adult: $26 \mathrm{~ms}$ vs 31 $\mathrm{ms}, \mathrm{H}=4.56281, p=0.030356)$. For the late-life group, there was no significant difference in response latency ( $25 \mathrm{~ms}$ vs 25 $\mathrm{ms}, \mathrm{H}=0.207598, p=0.653344)$.

We estimated the response latencies of 78 units in the extrastriate area MT, an area with one of the shortest response latencies in the extrastriate cortex (Schmolesky et al., 1998). Pooling the measurements collected in all cases, the median response latency was estimated $50.0 \mathrm{~ms}$ (Fig. 12), which is significantly longer than the median values estimated from the LGN sample $(\mathrm{H}=127.393, p=$ 1.85847e-38, comparing all LGN and MT neurons with receptive fields inside or on the boundaries of the physiological scotomas). The little overlap between the latency distributions for the LGN units (10\%-90\% percentile: $22-36 \mathrm{~ms}$ ) and the MT units (10\%-90\%-percentile: 40-63 ms) suggests that the LGN responses were mostly mediated by feedforward connections from the retina, and perhaps other subcortical sources, rather than from feedback connections from the cortex.

\section{Discussion}

In animals with V1 lesions introduced in infancy, adulthood, and late-life, we found that neurons with strong visually evoked responses were relatively abundant inside the LGN lesion projection zones. This finding was unexpected, given that previous studies in macaques reported that the removal of $\mathrm{V} 1$ or the occipital lobe resulted in almost complete depletion of neurons in the lesion projection zone (Vanburen, 1963; Mihailović et al., 1971; Dineen and Hendrickson, 1981; Dineen and Keating, 1981; Dineen et al., 1982; Hendrickson and Dineen, 1982; Cowey et al., 1989; Weller and Kaas, 1989; see also Boire et al., 2002). A possible explanation for this difference is that the number of surviving neurons was underestimated in previous studies, due to the difficulty in identifying atrophied neurons among glial cells in Nissl-stained preparations. This possibility was addressed by Atapour et al. (2017), who used NeuN immunohistochemistry to specifically label neurons, reporting that the neuronal density in the lesion projection zone was reduced to one-third of its normal value in adult-lesioned marmosets, a significant, but far from complete cell loss. The type of lesion used in the present study involved both V1 and the white matter subjacent to this area, in both the occipital operculum and caudal parts of the calcarine sulcus. It is unknown whether the effects of this type of lesion differ from those of other types of lesions used in other studies (e.g., ischemic lesions) (Teo and Bourne, 2014). However, one would expect that the concurrent damage of superficial and deep portions of V1, and the intervening white matter, would likely result in greater degree of retrograde degeneration.

Although retinal axons terminate in the LGN lesion projection zone (Pasik et al., 1973; Dineen et al., 1982; Weller and Kaas, 1989; Kisvárday et al., 1991; Hendrickson et al., 2015), it had been unknown whether the surviving neurons remained physiologi- cally functional because alterations in the excitation/inhibition balance (Kisvárday et al., 1991) and atrophy of the cell bodies (Mihailović et al., 1971; Kisvárday et al., 1991; Boire et al., 2002; Atapour et al., 2017) have been observed. Despite these changes, we found that most of the surviving neurons responded robustly and reliably to visual stimuli. This finding is consistent with that of Tumosa et al. (1989), who also reported functional neurons in the cat LGN following combined lesions of areas 17 and 18.

\section{Retinotopy of the lesion projection zone}

If the normal retinotopy of the LGN was reorganized following V1 lesions, such that the receptive fields of surviving neurons were shifted to locations outside the physiological scotoma, these neurons, even if functional, would be unable to support blindsight. Plasticity of this type is well documented in animals with lesions of the retina or the visual cortex (Kaas et al., 1990; Gilbert and Wiesel, 1992; Chino et al., 1995; Darian-Smith and Gilbert, 1995; Schmid et al., 1996; Calford et al., 2000; Rosa et al., 2000; Baker et al., 2005; Wandell and Smirnakis, 2009, Shao et al., 2013; Papanikolaou et al., 2014). Importantly, this reorganization has also been observed in the LGN of cats with retinal lesions (Eysel et al., 1980; Eysel, 1982). Given that lesioning V1 also results in the loss of retinal ganglion cells (Dineen and Hendrickson, 1981; Cowey et al., 1989; Weller and Kaas, 1989; Johnson and Cowey, 2000; Cowey et al., 2011; Hendrickson et al., 2015), one possible outcome would be that the receptive fields of many surviving neurons clustered near the scotoma boundary, which could contribute to the reorganized MT retinotopy in adult-lesioned marmosets (Rosa et al., 2000). However, except for one elec- 

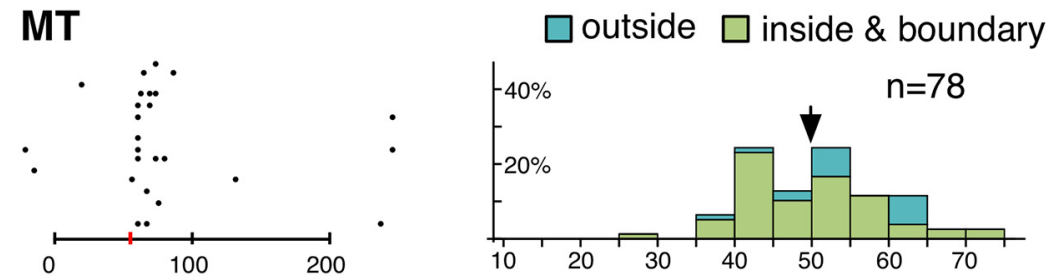

\section{parvo}
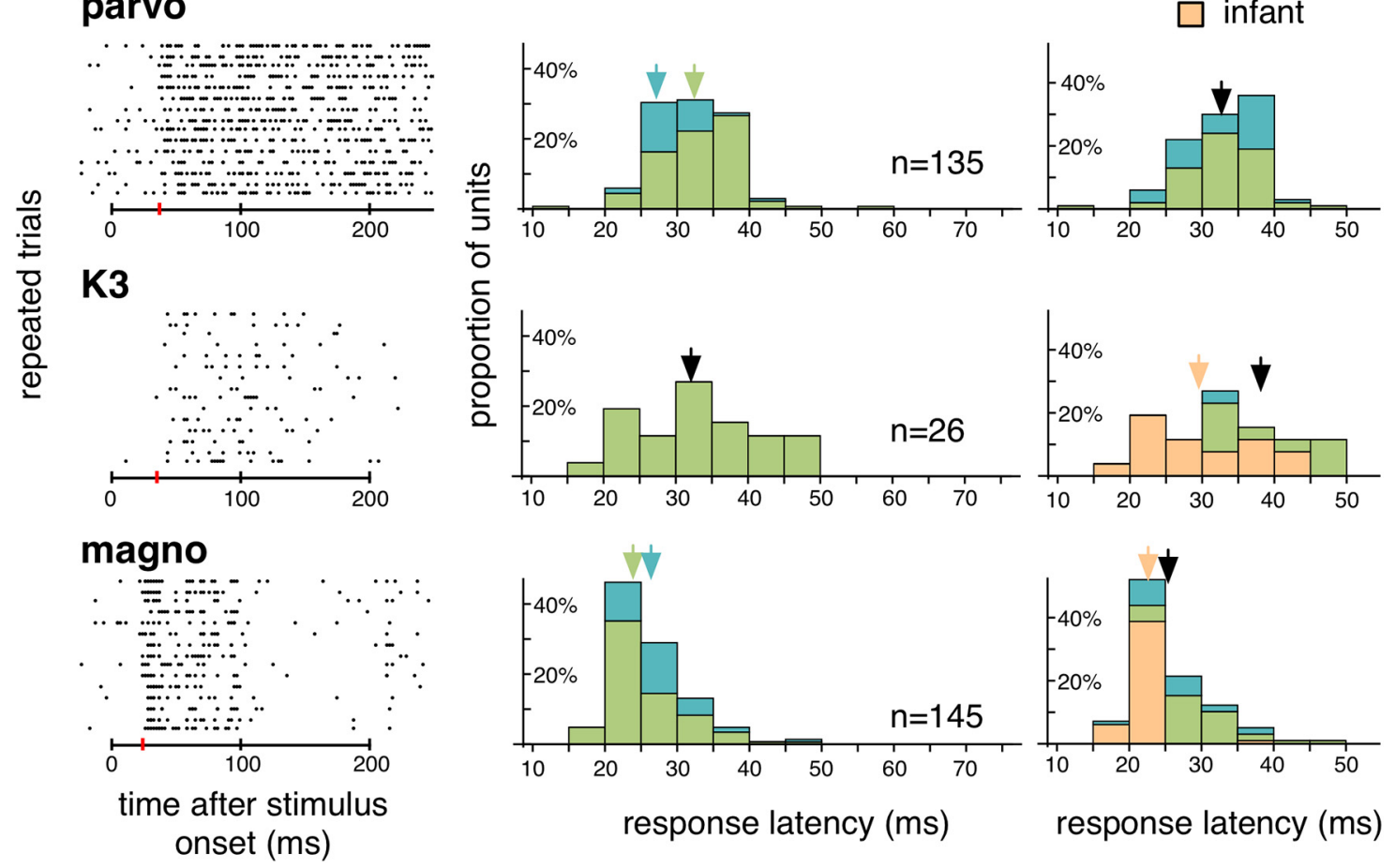

Figure 12. Left, The raster plots illustrate the responses of 4 representative units to 15 repeats of brief flashing stimulus that covered the receptive fields. They were sampled in (from top to bottom) the lesion projection zones of cortical area MT, the parvocellular, K3, and magnocellular layers of the LGN on the hemisphere ipsilateral to V1 lesion. Horizontal bar below each raster plot represents the time interval during which the stimulus was on. Red vertical bars represent the estimated response latencies $(55,37,35$, and $24 \mathrm{~ms}$ from top to bottom). Middle, The distributions of response latencies estimated for units pooled in all 6 cases. For each plot, the population was subdivided into units with receptive fields inside or on the boundaries of the physiological scotoma (green), and units with receptive fields outside the physiological scotoma (blue). Arrows indicate median values. If the difference between the subdivisions was not significant, a black arrow indicates the median value of the laminae. If the difference was significant, two color-coded arrows indicate the median values for the subdivisions. Median values for parvocellular units: $32 \mathrm{~ms}$ versus $27 \mathrm{~ms}$ $(H=13.6102 ; p=0.00016507)$. Median values for magnocellular units: $24 \mathrm{~ms}$ versus $26 \mathrm{~ms}(H=9.53708 ; p=0.00177862)$. Right, For units with receptive fields inside or on the boundaries of the physiological scotoma, the distributions are divided according to the age groups. Orange represents infant. Green represents adult. Blue represents late-life.

trode penetration (Fig. 5A), we did not find strong evidence for retinotopic reorganization.

Many surviving neurons had unexpectedly large receptive fields. A similar result has been reported in visual cortex that underwent lesion-induced reorganization (Gilbert and Wiesel, 1992; Eysel and Schweigart, 1999; Schweigart and Eysel, 2002; Shao et al., 2013; Papanikolaou et al., 2014), as well as in the cat LGN following combined lesions of areas 17 and 18 (Tumosa et al., 1989). In macaques with early-life V1 lesions, Hendrickson and Dineen (1982) observed that many spared LGN neurons had enlarged cell bodies and dendritic fields, which could provide an explanation for the enlarged receptive fields. However, as enlarged receptive fields were observed in all age groups, additional mechanisms, such as altered excitation/inhibition balance, are likely to be involved.

\section{Lamination in the lesion projection zone}

Intraocular tracer injections in V1-lesioned monkeys have revealed that retinal axons terminate in ocularly segregated layers within the lesion projection zones (Dineen et al., 1982; Weller and Kaas, 1989; Kisvárday et al., 1991, Hendrickson et al., 2015), suggesting that ocular dominance patterns are preserved. This expectation was met in all 6 of our cases. In addition, we also found evidence for physiological distinction of parvocellular, magnocellular, and koniocellular neurons.

The removal of V1 results in retrograde degeneration of retinal ganglion cells, which is significantly more severe if the lesion occurs in infancy (Dineen and Hendrickson, 1981; Weller and Kaas, 1989; Hendrickson et al., 2015). This degeneration is largely selective to the $\mathrm{P} \beta$ ganglion cells, which project mainly to the parvocellular layers of the LGN (Dineen et al., 1982; Cowey et al., 1989). This is consistent with our finding that parvocellular layers were often nonresponsive. We were unable to find parvocellular units in W2E, which was also compatible with the higher susceptibility to degeneration following lesions in early life.

\section{The geniculocortical pathway in lesioned animals}

In macaques, LGN relay neurons project directly to extrastriate areas (Benevento and Yoshida, 1981; Fries, 1981; Yukie and Iwai, 1981; Bullier and Kennedy, 1983; Lysakowski et al., 1988; Sincich et al., 2004). These connections are retained following lesions of V1 (Yukie and Iwai, 1981; Hendrickson and Dineen, 1982; 
Cowey and Stoerig, 1989; Kisvárday et al., 1991; Warner et al., 2015), providing a pathway for visual information to reach extrastriate areas. Relay neurons are primarily found in koniocellular layers. In macaques with adulthood V1 lesions, the rest of the lesion projection zone appears to be dominated by GABAergic neurons (Kisvárday et al., 1991). If this finding also applies to marmosets lesioned at different ages, many of the units we sampled in the parvocellular and the magnocellular layers could be interneurons. In the normal LGN, interneurons provide inhibition for relay neurons. They have larger receptive fields than relay neurons and are believed to have important roles in refining their response characteristics (Martinez et al., 2014; Hirsch et al., 2015; Cox and Beatty, 2017). Alternatively, they can also be GABAergic projection neurons (Lee et al., 2014) that become evident as part of the plastic process. Future studies combining tracing and immunocytochemistry are needed to clarify this issue.

Kisvárday et al. (1991) suggested that relay neurons in the lesion projection zone are driven by an indirect pathway via the superior colliculus (see also Stepniewska et al., 1999). Although this issue requires further investigation, it is noteworthy that the range of response latencies of our K3 units overlapped almost completely with other LGN unit. In addition, as the response latency of our LGN units showed almost no overlap with those estimated for MT unit (which are among the shortest in the visual cortex) (Schmolesky et al., 1998), it is likely that the surviving neurons are primarily driven by retinal feedfoward connections, rather than cortical feedback connections (Sillito et al., 2006).

\section{The effects of lesion time}

It has long been noted that the enhanced plasticity of the brain in early stages of development is associated with greater ability to recover from physical damages (Hubel and Wiesel, 1970; Payne and Cornwell, 1994; Payne et al., 1996; Payne and Lomber, 2002; Guzzetta et al., 2010; Anderson et al., 2011). The normal retinotopy of area MT in marmosets, for example, is maintained only if V1 lesions are introduced in early life (Yu et al., 2013). The fact that we observed only subtle differences in the response characteristics of the neurons in our three age groups suggests that lesion-age effects are likely to be mediated at the level of the cortex, or by other subcortical nuclei. The pathway from the retina to the inferior pulvinar, and then to area MT, is a likely candidate, as this pathway has been reported to be strengthened if V1 lesions are introduced in early life (Warner et al., 2015). Our finding is consistent with that of Tumosa et al. (1989), who also failed to find significant differences in the response characteristics of cat LGN neurons following lesions of area 17/18 at different developmental stages.

Aging increases the vulnerability of neurons (Mattson and Magnus, 2006), but very little is known about its effects on the visual pathways in lesioned animals. Atapour et al. (2017) reported that marmosets with late-life V1 lesions displayed greater loss of LGN neurons than animals subjected to lesions earlier in adulthood. However, in terms of physiology, we were not able to observe obvious negative effects in our late-life group.

In conclusion, our findings suggest that the LGN is physiologically viable for supporting blindsight in animals with V1 lesions introduced at any age.

\section{References}

Ajina S, Pestilli F, Rokem A, Kennard C, Bridge H (2015) Human blindsight is mediated by an intact geniculo-extrastriate pathway. eLife 4:e08935. CrossRef Medline

Anderson V, Spencer-Smith M, Wood A (2011) Do children really recover better? Neurobehavioural plasticity after early brain insult. Brain 134: 2197-2221. CrossRef Medline

Atapour N, Worthy KH, Lui LL, Yu HH, Rosa MG (2017) Neuronal degeneration in the dorsal lateral geniculate nucleus following lesions of primary visual cortex: comparison of young adult and geriatric marmoset monkeys. Brain Struct Funct 222:3283-3293. CrossRef Medline

Baker CI, Peli E, Knouf N, Kanwisher NG (2005) Reorganisation of visual processing in macular degeneration. J Neurosci 25:614-618. CrossRef Medline

Baringhaus L, Franz C (2004) On a new multivariate two-sample test. J Multivar Anal 88:190-206. CrossRef

Benevento LA, Yoshida K (1981) The afferent and efferent organization of the lateral geniculo-prestriate pathways in the macaque monkey. J Comp Neurol 203:455-474. CrossRef Medline

Berman RA, Wurtz RH (2010) Functional identification of a pulvinar path from superior colliculus to cortical area MT. J Neurosci 30:6342-6354. CrossRef Medline

Berman RA, Wurtz RH (2011) Signals conveyed in the pulvinar pathway from superior colliculus to cortical area MT. J Neurosci 31:373-384. CrossRef Medline

Blythe IM, Kennard C, Ruddock KH (1987) Residual vision in patients with retrogeniculate lesions of the visual pathways. Brain 110:887-905. CrossRef Medline

Boire D, Théoret H, Ptito M (2002) Stereological evaluation of neurons and glia in the monkey dorsal lateral geniculate nucleus following an early cerebral hemispherectomy. Exp Brain Res 142:208-220. CrossRef Medline

Bourne JA, Rosa MG (2006) Hierarchical development of the primate visual cortex, as revealed by neurofilament immunoreactivity: early maturation of the middle temporal area (MT). Cereb Cortex 16:405-414. CrossRef Medline

Bullier J, Kennedy H (1983) Projection of the lateral geniculate nucleus onto cortical area V2 in the macaque monkey. Exp Brain Res 53:168-172. Medline

Calford MB, Wang C, Taglianetti V, Waleszczyk WJ, Burke W, Dreher B (2000) Plasticity in adult cat visual cortex (area 17) following circumscribed monocular lesions of all retinal layers. J Physiol 524:587-602. CrossRef Medline

Chandolia RK, Luetjens CM, Wistuba J, Yeung CH, Nieschlag E, Simoni M (2006) Changes in endocrine profile and reproductive organs during puberty in the male marmoset monkey (Callithrixjacchus). Reproduction 132:355-363. CrossRef Medline

Chaplin TA, Yu HH, Rosa MG (2013) Representation of the visual field in the primary visual area of the marmoset monkey: magnification factors, point-image size, and proportionality to retinal ganglion cell density. J Comp Neurol 521:1001-1019. CrossRef Medline

Chino YM, Smith EL 3rd, Kaas JH, Sasaki Y, Cheng H (1995) Receptivefield properties of deafferentated visual cortical neurons after topographic map reorganisation in adult cats. J Neurosci 15:2417-2433. Medline

Cowey A (2010) The blindsight saga. Exp Brain Res 200:3-24. CrossRef Medline

Cowey A, Stoerig P (1989) Projection patterns of surviving neurons in the dorsal lateral geniculate nucleus following discrete lesions of striate cortex: implications for residual vision. Exp Brain Res 75:631-638. Medline

Cowey A, Stoerig P, Perry VH (1989) Transneuronal retrograde degeneration of retinal ganglion cells after damage to striate cortex in macaque monkeys: selective loss of $\mathrm{P} \beta$ cells. Neuroscience 29:65-80. CrossRef Medline

Cowey A, Alexander I, Stoerig P (2011) Transneuronal retrograde degeneration of retinal ganglion cells and optic tract in hemianopic monkeys and humans. Brain 134:2149-2157. CrossRef Medline

Cox CL, Beatty JA (2017) The multifaceted role of inhibitory interneurons in the dorsal lateral geniculate nucleus. Vis Neurosci 34:E017. CrossRef Medline

Darian-Smith C, Gilbert CD (1995) Topographic reorganisation in the striate cortex of the adult cat and monkey is cortically mediated. J Neurosci 15:1631-1647. Medline

Derrington AM, Lennie P (1984) Spatial and temporal contrast sensitivities of neurones in lateral geniculate nucleus of macaque. J Physiol 357:219 240. CrossRef Medline

Dineen J, Keating EG (1981) The primate visual system after bilateral removal of striate cortex. Exp Brain Res 41:338-345. Medline 
Dineen JT, Hendrickson AE (1981) Age-correlated differences in the amount of retinal degeneration after striate cortex lesions in monkeys. Invest Ophthalmol Vis Sci 21:749-752. Medline

Dineen J, Hendrickson A, Keating EG (1982) Alterations of retinal inputs following striate cortex removal in adult monkey. Exp Brain Res 47:446456. Medline

Eysel UT (1982) Functional reconnections without new axonal growth in a partially denervated visually relay nucleus. Nature 299:442-444. CrossRef Medline

Eysel UT, Schweigart G (1999) Increased receptive field size in the surround of chronic lesions in the adult cat visual cortex. Cereb Cortex 9:101-109. CrossRef Medline

Eysel UT, Gonzalez-Aguilar F, Mayer U (1980) A functional sign of reorganisation in the visual system of adult cats: later; geniculate neurons with displaced receptive fields after lesions of the nasal retina. Brain Res 181: 285-300. CrossRef Medline

Friedman HS, Priebe CE (1998) Estimating stimulus response latency. J Neurosci Methods 83:185-194. CrossRef Medline

Fries W (1981) The projection from the lateral geniculate nucleus to the prestriate cortex of the macaque. Proc R Soc Lond B 213:73-86. CrossRef Medline

Fritsches KA, Rosa MG (1996) Visuotopic organisation of striate cortex in the marmoset monkey (Callithrix jacchus). J Comp Neurol 372:264-282. CrossRef Medline

Fritschy JM, Garey LJ (1986a) Quantitative changes in morphological parameters in the developing visual cortex of the marmoset monkey. Dev Brain Res 29:173-188. CrossRef Medline

Fritschy JM, Garey JL (1986b) Postnatal development of quantitative morphological parameters in the lateral geniculate nucleus of the marmoset monkey. Dev Brain Res 30:157-168. CrossRef Medline

Gallyas F (1979) Silver staining of myelin by means of physical development. Neurol Res 1:203-209. CrossRef Medline

Gilbert CD, Wiesel TN (1992) Receptive field dynamics in adult primary visual cortex. Nature 356:150-152. CrossRef Medline

Gross CG, Moore T, Rodman HR (2004) Visually guided behavior after V1 lesions in young and adult monkeys and its relation to blindsight in humans. Prog Brain Res 144:279-294. CrossRef Medline

Guzzetta A, D'Acunto G, Rose S, Tinelli F, Boyd R, Cioni G (2010) Plasticity of the visual system after early brain damage. Dev Med Child Neurol 52:891-900. CrossRef Medline

Hendrickson A, Dineen JT (1982) Hypertrophy of neurons in dorsal lateral geniculate nucleus following striate cortex lesions in infant monkeys. Neurosci Lett 30:217-322. CrossRef Medline

Hendrickson A, Warner CE, Possin D, Huang J, Kwan WC, Bourne JA (2015) Retrograde transneuronal degeneration in the retina and lateral geniculate nucleus of the V1-lesioned marmoset monkey. Brain Struct Funct 220:351-360. CrossRef Medline

Hirsch JA, Wang X, Sommer FT, Martinez LM (2015) How inhibitory circuits in the thalamus serve vision. Annu Rev Neurosci 38:309-329. CrossRef Medline

Holmes G (1918) Disturbances of vision by cerebral lesions. Br J Ophthalmol 2:353-384. CrossRef Medline

Horton JC, Hoyt WF (1991) The representation of the visual field in human striate cortex: a revision of the classic Holmes map. Arch Ophthalmol 109:816-824. CrossRef Medline

Hubel DH, Wiesel TN (1970) The period of susceptibility to the physiological effects of unilateral eye closure in kittens. J Physiol 206:419-436. CrossRef Medline

Johnson H, Cowey A (2000) Transneuronal retrograde degeneration of retinal ganglion cells following restricted lesions of striate cortex in the monkey. Exp Brain Res 132:269-275. CrossRef Medline

Kaas JH, Krubitzer LA, Chino YM, Langston AL, Polley EH, Blair N (1990) Reorganization of retinotopic cortical maps in adult mammals after lesions of the retina. Science 248:229-231. CrossRef Medline

Kisvárday ZF, Cowey A, Stoerig P, Somogyi P (1991) Direct and indirect retinal input into degenerated dorsal lateral geniculate nucleus after striate cortical removal in monkey: implications for residual vision. Exp Brain Res 86:271-292. Medline

Lee AT, Vogt D, Rubenstein JL, Sohal VS (2014) A class of GABAergic neurons in the prefrontal cortex sends long-range projections to the nucleus accumbens and elicits acute avoidance behavior. J Neurosci 34:1151911525. CrossRef Medline
Leopold DA (2012) Primary visual cortex: awareness and blindsight. Annu Rev Neurosci 35:91-109. CrossRef Medline

Lui LL, Mokri Y, Reser DH, Rosa MG, Rajan R (2015) Responses of neurons in the marmoset primary auditory cortex to interaural level differences: comparison of pure tones and vocalizations. Front Neurosci 9:e132. CrossRef Medline

Lysakowski A, Standage GP, Benevento LA (1988) An investigation of collateral projections of the dorsal lateral geniculate nucleus and other subcortical structures to cortical areas V1 and V4 in the macaque monkey: a double label retrograde tracer study. Exp Brain Res 69:651-661. Medline

Martinez LM, Molano-Mazón M, Wang X, Sommer FT, Hirsch JA (2014) Statistical wiring of thalamic receptive fields optimizes spatial sampling of the retinal image. Neuron 81:943-956. CrossRef Medline

Matthews MR, Cowan WM, Powell TP (1960) Transneuronal cell degeneration in the lateral geniculate nucleus of the macaque monkey. J Anat 94:145-169. Medline

Mattson MP, Magnus T (2006) Ageing and neuronal vulnerability. Nat Rev Neurosci 7:278-294. CrossRef Medline

Mihailović LT, Čupić D, Dekleva N (1971) Changes in the numbers of neurons and glial cells in the lateral geniculate nucleus of the monkey during retrograde cell degeneration. J Comp Neurol 142:223-229. CrossRef Medline

Missler M, Eins S, Merker HJ, Rothe H, Wolff JR (1993a) Pre- and postnatal development of the primary visual cortex of the common marmoset: I. A changing space for synaptogenesis. J Comp Neurol 333:41-52. CrossRef Medline

Missler M, Wolff A, Merker HJ, Wolff JR (1993b) Pre- and postnatal development of the primary visual cortex of the common marmoset: II. Formation, remodelling, and elimination of synapses as overlapping processes. J Comp Neurol 333:53-67. CrossRef Medline

Moore T, Rodman HR, Repp AB, Gross CG, Mezrich RS (1996) Greater residual vision in monkeys after striate cortex damage in infancy. J Neurophysiol 76:3928-3933. CrossRef Medline

Mundinano IC, Kwan CK, Bourne JA (2015) Mapping the mosaic sequence of primate visual cortical development. Front Neuroanat 9:132. CrossRef Medline

Nishijima K, Saitoh R, Tanaka S, Ohsato-Suzuki M, Ohno T, Kitajima S (2012) Life span of common marmoset (Callithrix jacchus) at CLEA Japan breeding colony. Biogerontology 13:439-443. CrossRef Medline

Papanikolaou A, Keliris GA, Papageorgiou TD, Shao Y, Krapp E, Papageorgiou E, Stingl K, Bruckmann A, Schiefer U, Logothetis NK, Smirnakis SM (2014) Population receptive field analysis of the primary visual cortex complements perimetry in patients with homonymous visual field defects. Proc Natl Acad Sci U S A 111:E1656-E1665. CrossRef Medline

Pasik P, Pasik T, Hámori J, Szentágothal J (1973) Golgi type II interneurones in the neural circuit of the monkey lateral geniculate nucleus. Exp Brain Res 17:18-34. Medline

Paxinos G, Watson C, Petrides M, Rosa MG, Tokuno H (2012) The marmoset brain in stereotaxic coordinates. San Diego, CA: Academic.

Payne BR, Cornwell P (1994) System-wide repercussions of damage to the immature visual cortex. Trends Neurosci 17:126-130. CrossRef Medline

Payne BR, Lomber SG (2002) Plasticity of the visual cortex after injury: what's different about the young brain? Neuroscientist 8:174-185. CrossRef Medline

Payne BR, Lomber SG, Macneil MA, Cornwell P (1996) Evidence for greater sight in blindsight following damage of primary visual cortex early in life. Neuropsychologia 34:741-774. CrossRef Medline

R Core Team (2013) R: a language and environment for statistical computing. Vienna, Austria: R Foundation for Statistical Computing. http:// www.R-project.org/.

Rajan R, Dubaj V, Reser DH, Rosa MG (2013) Auditory cortex of the marmoset monkey: complex responses to tones and vocalizations under opiate anaesthesia in core and belt areas. Eur J Neurosci 37:924-941. CrossRef Medline

Rodman HR, Gross CG, Albright TD (1990) Afferent basis of visual response properties in area MT of the macaque: II. Effects of superior colliculus removal. J Neurosci 10:1154-1164. Medline

Rosa MG, Elston GN (1998) Visuotopic organisation and neuronal response selectivity for direction of motion in visual areas of the caudal temporal lobe of the marmoset monkey (Callithrix jacchus): middle temporal area, middle temporal crescent, and surrounding cortex. J Comp Neurol 393:505-527. CrossRef Medline 
Rosa MG, Tweedale R, Elston GN (2000) Visual responses of neurons in the middle temporal area of new world monkeys after lesions of striate cortex. J Neurosci 20:5552-5563. Medline

Roy S, Jayakumar J, Martin PR, Dreher B, Saalmann Y, Hu D, Vidyasagar TR (2009) Segregation of short-wavelength-sensitive (S) cone signals in the macaque dorsal lateral geniculate nucleus. Eur J Neurosci 30:1517-1526. CrossRef Medline

Sanders MD, Warrington EK, Marshall J, Wieskrantz L (1974) "Blindsight": vision in a field detect. Lancet 1:707-708. Medline

Schmid LM, Rosa MG, Calford MB, Ambler JS (1996) Visuotopic reorganization in the primary visual cortex of adult cats following monocular and binocular lesions. Cereb Cortex 6:388-405. CrossRef Medline

Schmid MC, Mrowka SW, Turchi J, Saunders RC, Wilke M, Peters AJ, Ye FQ, Leopold DA (2010) Blindsight depends on the lateral geniculate nucleus. Nature 466:373-377. CrossRef Medline

Schmolesky MT, Wang Y, Hanes DP, Thompson KG, Leutgeb S, Schall JD, Leventhal AG (1998) Signal timing across the macaque visual system. J Neurophysiol 79:3272-3278. CrossRef Medline

Schweigart G, Eysel UT (2002) Activity-dependent receptive field changes in the surround of adult cat visual cortex lesions. Eur J Neurosci 15:15851596. CrossRef Medline

Shao Y, Keliris GA, Papanikolaou A, Fischer MD, Zobor D, Jägle H, Logothetis NK, Smirnakis SM (2013) Visual cortex organisation in a macaque monkey with macular degeneration. Eur J Neurosci 38:3456-3464. CrossRef Medline

Sillito AM, Cudeiro J, Jones HE (2006) Always returning: feedback and sensory processing in visual cortex and thalamus. Trends Neurosci 29:307316. CrossRef Medline

Silvanto J, Rees G (2011) What does neural plasticity tell us about role of primary visual cortex (V1) in visual awareness? Front Psychol 2:e6. CrossRef Medline

Silverman MS, Tootell RB (1987) Modified technique for cytochrome oxidase histochemistry: increased staining intensity and compatibility with 2-deoxyglucose autoradiography. J Neurosci Methods 19:1-10. CrossRef Medline

Sincich LC, Park KF, Wohlgemuth MJ, Horton JC (2004) Bypassing V1: a direct geniculate input to area MT. Nat Neurosci 7:1123-1128. CrossRef Medline

Spatz WB (1978) The retino-geniculo-cortical pathway in Callithrix: I. Intraspecific variations in the lamination pattern of the lateral geniculate nucleus. Exp Brain Res 33:553-563. Medline

Stepniewska I, Qi HX, Kaas JH (1999) Do superior colliculus projection zones in the inferior pulvinar project to MT in primates? Eur J Neurosci 11:469-480. CrossRef Medline
Teo L, Bourne JA (2014) A reproducible and translatable model of focal ischemia in the visual cortex of infant and adult marmoset monkeys. Brain Pathol 24:459-474. CrossRef Medline

Tumosa N, McCall MA, Guido W, Spear PD (1989) Responses of lateral geniculate neurons that survive long-term visual cortex damage in kittens and adult cats. J Neurosci 9:280-298. Medline

Vanburen JM (1963) Trans-synaptic retrograde degeneration in the visual system of primates. J Neurol Neurosurg Psychiatry 26:402-409. CrossRef Medline

Wandell BA, Smirnakis SM (2009) Plasticity and stability of visual field maps in adult primary visual cortex. Nat Rev Neurosci 10:873-884. CrossRef Medline

Warner CE, Goldshmit Y, Bourne JA (2010) Retinal afferents synapse with relay cells targeting the middle temporal area in the pulvinar and lateral geniculate nuclei. Front Neuroanat 4:8. CrossRef Medline

Warner CE, Kwan WC, Wright D, Johnston LA, Egan GF, Bourne JA (2015) Preservation of vision by the pulvinar following early-life primary visual cortex lesions. Curr Biol 25:424-434. CrossRef Medline

Weller RE, Kaas JH (1989) Parameters affecting the loss of ganglion cells of the retina following ablations of striate cortex in primates. Vis Neurosci 3:327-349. CrossRef Medline

Werth R (2006) Visual functions without the occipital lobe or after cerebral hemispherectomy in infancy. Eur J Neurosci 24:2932-2944. CrossRef Medline

White AJ, Wilder HD, Goodchild AK, Sefton AJ, Martin PR (1998) Segregation of receptive field properties in the lateral geniculate nucleus of a new-world monkey, the marmoset Callithrix jacchus. J Neurophysiol 80: 2063-2076. CrossRef Medline

Yu HH, Rosa MG (2010) A simple method for creating wide-field visual stimulus for electrophysiology: mapping and analyzing receptive fields using a hemispheric display. J Vis 10:15. CrossRef Medline

Yu HH, Chaplin TA, Davies AJ, Verma R, Rosa MG (2012) A specialized area in limbic cortex for fast analysis of peripheral vision. Curr Biol 22: 1351-1357. CrossRef Medline

Yu HH, Chaplin TA, Egan GW, Reser DH, Worthy KH, Rosa MG (2013) Visually evoked responses in extrastriate area MT after lesions of striate cortex in early life. J Neurosci 33:12479-12489. CrossRef Medline

Yukie M, Iwai E (1981) Direct projection from the dorsal lateral geniculate nucleus to the prestriate cortex in macaque monkeys. J Comp Neurol 201:81-97. CrossRef Medline

Zeater N, Cheong SK, Solomon SG, Dreher B, Martin PR (2015) Binocular visual responses in the primate lateral geniculate nucleus. Curr Biol 25: 3190-3195. CrossRef Medline 